\title{
Research on prediction model of drilling force in CFRP internal chip removal hole drilling based on SVR
}

Chengyang Xu ( $\sim$ xuchengyang1989101@163.com )

Shenyang Aerospace University

\section{Yao Songyang}

Shenyang Aerospace University

\section{Wang Gongdong}

Shenyang Aerospace University

\section{Wang Yiwen}

Harbin University of Science and Technology

\section{Xu Jiazhong}

Harbin University of Science and Technology

\section{Research Article}

Keywords: CFEP, Internal chip removal hole drilling, Drilling force, Support vector regression, Prediction model

Posted Date: February 17th, 2021

DOl: https://doi.org/10.21203/rs.3.rs-239631/v1

License: (c) (i) This work is licensed under a Creative Commons Attribution 4.0 International License. Read Full License

Version of Record: A version of this preprint was published at The International Journal of Advanced Manufacturing Technology on August 8th, 2021. See the published version at https://doi.org/10.1007/s00170-021-07766-0. 


\title{
Research on prediction model of drilling force in CFRP internal chip removal hole drilling based on SVR
}

\author{
Chengyang $\mathrm{Xu}^{1} \cdot$ Songyang Yao ${ }^{1} \cdot$ Gongdong Wang $^{1} \cdot$ Yiwen Wang $^{2} \cdot J^{\prime a z h o n g} \mathrm{Xu}^{3}$
}

\begin{abstract}
Drilling force is the main factor affecting the drilling quality and tool wear of carbon fiber reinforced resin matrix composites (CFRP), selecting the appropriate process parameters can effectively control the drilling force, improve the drilling quality and tool life. In this paper, in order to accurately predict and effectively control the drilling force under the process of internal chip removal hole drilling: Firstly, based on the application of support vector regression (SVR) in data analysis, the theory of the prediction model of drilling force in CFRP is given; Secondly, on the basis of the above theories, the experiment of chip removal in CFRP is designed and completed, designed and completed the CFRP internal chip removal processing drilling experiment, it provides preparation for the solution of parameters in the subsequent model; Again, based on the above theoretical analysis and experimental data, under the premise of choosing the appropriate kernel function and loss function, the sequential minimum optimization (SMO) algorithm is applied to solve the unknown parameters in the model, to complete the construction of the SVR-based CFRP internal chip removal machining drilling force prediction model; Finally, using the constructed predictive model, it is predicted that when CFRP internal chip removal hole machining is studied, The relationship between cutting parameters (speed, feed), tool parameters (drill diameter, peak angle, relief angle) and suction parameters (negative pressure) and axial force.
\end{abstract}

Keywords CFEP, Internal chip removal hole drilling, Drilling force, Support vector regression, Prediction model

$\triangle$ Chengyang Xu

Xuchengyang199101@163.com

1 College of Aerospace Engineering, Shenyang Aerospace University, Shenyang 110136, China

2 School of Mechanical and Power Engineering, Harbin University of Science and Technology, Harbin 150080, China

3 School of Automation Engineering, Harbin University of Science and Technology, Harbin 150080, China

\section{Introduction}

Drilling force is the main factor affecting the quality of CFRP holes and tool wear, its size is closely related to tool parameters and cutting parameters. If the parameter selection is not appropriate, it may cause excessive drilling force, and then the defects such as delamination and tearing are produced [1]. Accurate prediction and effective control of drilling force in CFRP machining are the necessary conditions to ensure the quality of CFRP drilling and reduce tool wear [2]. Therefore, study the relationship between drilling force and various influencing factors, establish prediction model of CFRP drilling force, it is an urgent problem to be solved to improve the quality of hole making and the life of cutting tools.

At present, scholars at home and abroad have conducted extensive and in-depth research on the drilling force generated in the process of CFRP drilling. For example, in 1990, Hocheng et al. [3] pointed out that the critical axial force is related to the cutting depth and the material properties of the machined object. In 1995, Chandrasekharan et al. [4] established the prediction model of axial force and torque for drilling CFRP materials. In 2005, Sun et al. [5] adopted the method of CFRP drilling experiment, The influence of cutting tool material (high speed steel and cemented carbide), cutting parameters, drilling number and material thickness on drilling force is analyzed. In 2008, Tsao et al. [6] studied the relationship between bit diameter, feed rate and drilling force when using candle core drill to process CFRP. In 2013, Ren et al. [7] Based on the cutting model of multilayer composite materials, based on the analysis of the interaction between cutting edge and matrix and fiber, the relationship model between cutting edge and cutting parameters is established and verified by experiments. In 2016, Hu et al. [8] gave a drilling force model when processing CFRP using the pecking drilling method, and conducted an in-depth study on the relationship between the drilling force, tool wear and chip shape in this processing method. In 2017, Liu et al. [9] established a fullcycle prediction model for the axial force in different drilling stages. In 2018, Meng et al. [10] Based on the experimental data obtained by drilling and machining unidirectional CFRP 
plates, based on the analysis of the changing law of the drilling force in any cycle of the drilling process, a full-period prediction model of the drilling force of CFRP for hole making is established, and the relationship between the damage around the hole and the drilling force is studied using this model.

From the above analysis, it can be seen that in the drilling process, there is a nonlinear relationship between drilling force and parameters such as tool parameters and processing parameters, in order to accurately predict the drilling force, this nonlinear relationship needs to be solved [11-13]. As a method of solving nonlinear problems, SVR is different from previous statistical methods. It can also maintain excellent solution performance in the case of small samples, while traditional statistical learning methods can only obtain the optimal solution when the sample tends to infinity $[14,15]$. When constructing the SVR parameterized model, the solution process is only determined by a small number of support vectors, not all sample data, so that the complexity of its calculation depends on the number of support vectors, rather than the dimensionality of the input sample space. Since the complexity of its calculation does not depend on the dimensionality of the sample space, it avoids the problem of solving problems caused by the "curse of dimensionality" in a sense [16-18]. The internal chip removal drilling process is a new type of CFRP green hole making process, and the research on its drilling force prediction model is still rare, therefore, this article will build on the SVR theory as a basis to construct a drilling force prediction model for internal chip removal and hole making, To realize the effective control of the drilling force in hole making, and it can also provide a reference for the selection of drilling process parameters [19].

\section{Construction theory of drilling force prediction model}

In order to carry out internal chip removal processing drilling force prediction model construction theoretical research: First, the composition and working principle of the suction type internal chip removal system for CFRP internal chip removal processing are given; second, the construction theory of the SVR-based CFRP internal chip removal processing drilling force prediction model is given.

\subsection{Composition and working principle of internal chip removal system}

The Suction-type internal chip removal system (Figure 1) is composed of machine tool, CFRP, inner-chip-removal drilling bit, external-rotation-internal-chip removal tool handle , chip pipe, chip collecting device and so on. The inner-chip-removal drilling bit and the external-rotation-internal-chip removal tool handle have chip removal holes. The function of the system is to discharge the chips generated in the drilling process of CFRP in real time through the Chip removal channel, reduce the cost of manpower and material resources, improve the efficiency and quality of drilling, and realize the green processing of CFRP. The working principle of the system is that, when the machine tool is working, the spindle drives the suction type inner-chip-removal drilling bit installed on the external and external-rotation-internal-chip removal tool handle to drill. At the same time, the fan in the chip collecting device provide the power to absorb chips (negative pressure), the system uses the negative pressure to suck chips out through the chips suction channel of the drill bit, and sucks the chips through the chip removal channel of the drill bit and the external-rotation-internal-chip removal tool handle with the chips removal channel into the chip collecting device, thus completing the process of the aspiration-type internal chips removal drilling.

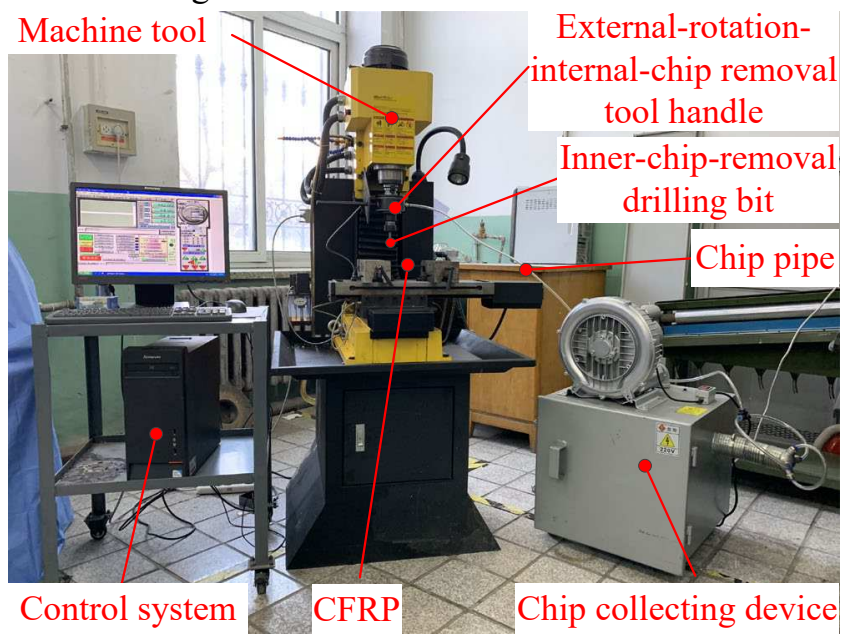

Fig.1 The Suction-type internal chip removal system

\subsection{Drilling force prediction model construction theory}

Based on the data set $\mathrm{S}=\left\{\left(\mathrm{x}^{1}, \mathrm{y}^{1}\right), \cdots\left(\mathrm{x}^{\mathrm{n}}, \mathrm{y}^{\mathrm{n}}\right)\right\}, \mathrm{S}=$ $\mathrm{X} \times \mathrm{Y}$ obtained from the experiments, the support vector regression is used to establish the drilling force prediction model for CFRP internal chip removal hole-making process, i.e. to find the optimal function $f(x)=\langle\omega, x\rangle+b$ to make $\mathrm{f}(\mathrm{x})$ be as close to $\mathrm{y}^{\mathrm{i}}$ as possible. At this point, the optimal curve $f(x)$ is the desired drilling force model. The tool parameters (drill diameter, peak angle, relief angle), cutting parameters (speed and feed rate), and aspirating parameters (negative pressure) are defined as the data set that affects the magnitude of drilling force, and the data set is denoted as a set $X . x^{i}=x_{1}^{i}, x_{2}^{i} \cdots x_{6}^{i} \in X$ is a vector that affects the magnitude of the drilling force, in which $\mathrm{x}^{\mathrm{i}}$ is the data of the tool parameters, the cutting parameters and the aspirating 
parameters corresponding to each component, and the drilling force data set obtained through experiment is defined as set $Y$, and $y^{i} \in Y$ set is the value of the drilling force obtained by the experiment. $\mathrm{y}^{\mathrm{i}}$ includes axial force $\mathrm{F}$ and torque $\mathrm{M}$. The data set of the relationship between the drilling force and each parameter obtained by the experiment is defined as set $\mathrm{S}=$ $\left(s^{1}, s^{2}, \cdots s^{n}\right)$, in which $s^{i}$ follows a certain distribution and the data is independent, $s^{i}=\left(x^{i}, y^{i}\right), x^{i} \in X, y^{i} \in Y$, and this data set is a training set made up of known sample information. $\omega$ is a vector consisting of the drilling force and the coefficients of the variables of tool parameters, cutting parameters as well as aspirating parameters of the CFRP internal chip removal hole-making process.

In order to ensure the prediction accuracy of the model, the $\varepsilon$-insensitive loss function is introduced, and the degree of loss between $\mathrm{y}$ and $\mathrm{f}(\mathrm{x})$ can be expressed as $\mathrm{c}(\mathrm{x}, \mathrm{y}, \mathrm{f}(\mathrm{x}))=$ $|\mathrm{y}-\mathrm{f}(\mathrm{x})|_{\varepsilon}=\max \{0,|\mathrm{y}-\mathrm{f}(\mathrm{x})|-\varepsilon\}$ then under this loss function, the value of $\omega$ can be obtained by the minimum $1 / 2\|\omega\|^{2}+C \sum_{i=1}^{n}\left|y^{i}-f\left(x^{i}\right)\right|_{\varepsilon}$. With the introduction of the slack variable, you can find the function $\mathrm{f}(\mathrm{x})$ by solving the minimum regularization problem of formula (1)

$$
\begin{array}{ll}
\min \left\{\frac{1}{2}\|\omega\|^{2}+C \sum_{i=1}^{n}\left(\xi_{i}+\xi_{i}^{*}\right)\right\} & \\
\text { s.t. }\left(\left\langle\omega, x^{i}\right\rangle+b\right)-y^{i} \leq \varepsilon+\xi_{i} & i=1,2, \cdots, n \\
y^{i}-\left(\left\langle\omega, x^{i}\right\rangle+b\right) \leq \varepsilon+\xi_{i}^{*} & i=1,2, \cdots, n \\
\xi_{i} \geq 0, \xi_{i}^{*} \geq 0 & i=1,2, \cdots, n
\end{array}
$$

Where, $\xi=\left(\xi_{1}, \xi_{2}, \cdots, \xi_{n}\right)^{\mathrm{S}}, \quad \xi^{*}=\left(\xi_{1}^{*}, \xi_{2}^{*}, \cdots, \xi_{\mathrm{n}}^{*}\right)^{\mathrm{S}}$ are the slack variables, and $\mathrm{C}$ is a penalty function that is used to adjust the errors.

Through further analysis, it is shown that solving equation (1) is equivalent to solving the duality. The function Lagrange is introduced to obtain the formula (2)

$$
\begin{aligned}
& L\left(\omega, b, \xi, \xi^{*}, \alpha, \beta, \eta, \eta^{*}\right)= \\
& \frac{1}{2}\|\omega\|^{2}+C \sum_{i=1}^{n}\left(\xi_{i}+\xi_{i}^{*}\right)-\sum_{i=1}^{n}\left(\eta_{i} \xi_{i}+\eta_{i}^{*} \xi_{i}^{*}\right) \\
& -\sum_{i=1}^{n} \alpha_{i}\left(\varepsilon+\xi_{i}+y^{i}-\left\langle\omega, x^{i}\right\rangle-b\right) \\
& -\sum_{i=1}^{n} \beta_{i}\left(\varepsilon+\xi_{i}^{*}-y^{i}+\left\langle\omega, x^{i}\right\rangle+b\right)
\end{aligned}
$$

Where, $\alpha_{i} \geq 0, \beta_{i} \geq 0, \eta_{i} \geq 0, \eta_{i}^{*} \geq 0, i=1,2, \cdots, n$. Then formula (3) to formula (6) can be given by the function extreme value condition:

$$
\begin{aligned}
& \nabla_{b} L=\sum_{i=1}^{n}\left(\alpha_{i}-\beta_{i}\right)=0 \\
& \nabla_{w} L=w-\sum_{i=1}^{n}\left(\alpha_{i}-\beta_{i}\right) x^{i}=0 \\
& \nabla_{\xi_{i}} L=C-\alpha_{i}-\eta_{i}=0 \\
& \nabla_{\xi_{\mathrm{i}}^{*}} \mathrm{~L}=\mathrm{C}-\beta_{\mathrm{i}}-\eta_{\mathrm{i}}^{*}=0
\end{aligned}
$$

Substitute formula (3) to the formula (6) into the formula (2), and seek the extreme maximum value with regard to $\alpha_{\mathrm{i}}$, $\beta_{\mathrm{i}}, \mathrm{i}=1,2, \cdots, \mathrm{n}$ for the formulae. The duality obtained is formula (7)

$$
\begin{aligned}
& \min _{i}, \beta_{i} \frac{1}{2} \sum_{i=1}^{n} \sum_{j=1}^{n}\left(\beta_{i}-\alpha_{i}\right)\left(\beta_{j}-\alpha_{j}\right)\left\langle x^{i}, x^{j}\right\rangle \\
& +\varepsilon \sum_{i=1}^{n}\left(\beta_{i}+\alpha_{i}\right)-\sum_{i=1}^{n} y^{i}\left(\beta_{i}-\alpha_{i}\right) \\
& \text { s.t. } \sum_{i=1}^{n}\left(\alpha_{i}-\beta_{i}\right), \quad 0 \leq \alpha_{i}, \beta_{i} \leq C, \quad i=1,2, \cdots, n
\end{aligned}
$$

If $\alpha_{\mathrm{i}}^{*}, \beta_{\mathrm{i}}^{*}$ is the optimal solutions to the above duality, the regression function $\mathrm{f}(\mathrm{x})$ can then be expressed as the formula (8)

$$
f(x)=\sum_{i=1}^{n}\left(\beta_{i}^{*}-\alpha_{i}^{*}\right)\left\langle x^{i}, x\right\rangle+b
$$

Where, $b$ can be calculated according to formula (9)

$$
b=\frac{1}{n} \sum_{j=1}^{n}\left(y^{j}-\sum_{i=1}^{n}\left(\beta_{i}^{*}-\alpha_{i}^{*}\right)\left\langle x^{j}, x^{i}\right\rangle\right)
$$

If $\beta_{\mathrm{i}}^{*}-\alpha_{\mathrm{i}}^{*} \neq 0$, then $\mathrm{x}^{\mathrm{i}}$ is known as a support vector.

For this nonlinear problem, the kernel function $\mathrm{K}\left(\mathrm{x}^{\mathrm{i}}, \mathrm{x}^{\mathrm{j}}\right)$ needs to be introduced. Then this regression problem is to find the nonlinear function $\mathrm{f}(\mathrm{x})=\langle\omega, \emptyset(\mathrm{x})\rangle+\mathrm{b}$, where $\omega, \varnothing(x) \in \kappa$. The principle of this nonlinear support vector regression problem is shown in Figure 2 and Figure 3 [20].

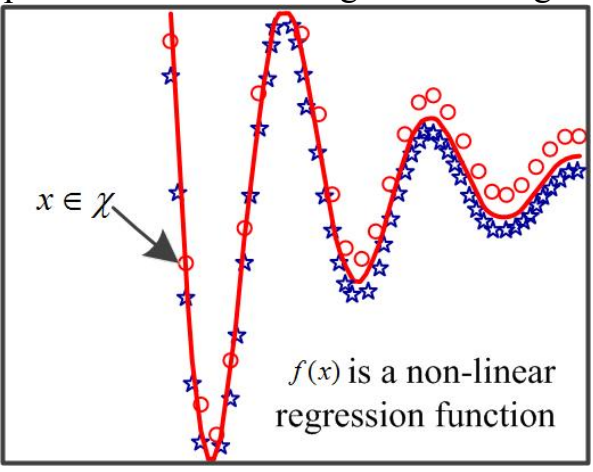

Fig.2 Nonlinear regression of data in oriinal input space $\chi$ 


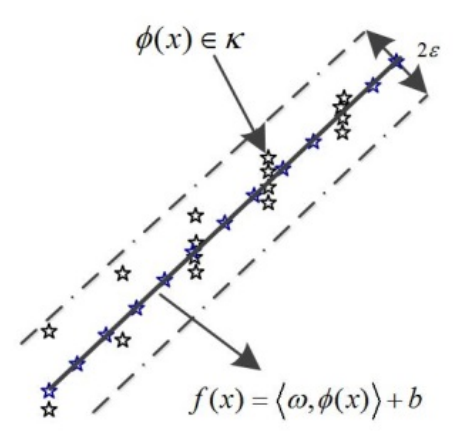

Fig.3 Linear regression of data in high dimensional characteristic space $\kappa$ obtained by special mapping $\phi$

At this point, the original optimization problem corresponding to the regression problem is formula (10)

$\min \left\{\frac{1}{2}\|\omega\|^{2}+C \sum_{i=1}^{n}\left(\xi_{i}+\xi_{i}^{*}\right)\right\}$

$$
\begin{array}{ll}
\text { s.t. } f\left(x^{i}\right)-y^{i} \leq \varepsilon+\xi_{i} & i=1,2, \cdots, n \\
y^{i}-f\left(x^{i}\right) \leq \varepsilon+\xi_{i}^{*} & i=1,2, \cdots, n \\
\xi_{i} \geq 0, \xi_{i}^{*} \geq 0 & i=1,2, \cdots, n
\end{array}
$$

As discussed above, the duality can be obtained, i.e. formula (11).

$$
\begin{aligned}
& \min _{\alpha_{i}, \beta_{i}} \frac{1}{2} \sum_{i=1}^{n} \sum_{j=1}^{n}\left(\beta_{i}-\alpha_{i}\right)\left(\beta_{j}-\alpha_{j}\right) K\left(x^{i}, x^{j}\right) \\
& +\varepsilon \sum_{i=1}^{n}\left(\beta_{i}+\alpha_{i}\right)-\sum_{i=1}^{n} y^{i}\left(\beta_{i}-\alpha_{i}\right) \\
& \text { s.t. } \sum_{i=1}^{n}\left(\alpha_{i}-\beta_{i}\right)=0,0 \leq \alpha_{i}, \beta_{i} \leq C, i=1,2, \cdots, n
\end{aligned}
$$

$\alpha_{i}^{*}, \beta_{i}^{*}$ are denoted as the optimal solutions of the above duality, and the regression function can then be expressed as the formula (12)

$$
f(x)=\sum_{i=1}^{n}\left(\beta_{i}^{*}-\alpha_{i}^{*}\right) K\left\langle x^{i}, x\right\rangle+b
$$

\subsection{Kernel function and loss function}

In order to obtain an accurate prediction model of drilling force for chip removal in CFRP, it is necessary to introduce appropriate kernel function and loss function when modeling. Therefore, in order to establish a high-precision prediction model between the parameters and drilling force, the loss function and kernel function used in this paper are selected, and the drilling force prediction model with loss function is given.

\section{(1) Kernel function}

As there is a nonlinear relationship between the drilling force and various parameters in the CFRP internal chip removal hole-making process, it is necessary to select the appropriate kernel function to construct the input space, to adapt to this nonlinear relationship, complete the establishment and solution of the drilling force prediction

\begin{tabular}{|c|c|}
\hline Name & Kernel function \\
\hline $\begin{array}{l}\text { Gaussian radial basis } \\
\text { kernel function }\end{array}$ & $\mathrm{K}(\mathrm{x}, \mathrm{y})=\exp \left(-\frac{\|\mathrm{x}-\mathrm{y}\|^{2}}{2 \sigma^{2}}\right)$ \\
\hline $\begin{array}{l}\text { Polynomial kernel } \\
\text { function }\end{array}$ & $\begin{array}{c}K(x, y)=(\langle x, y\rangle+c)^{P} \\
c \geq 0, P \geq 1\end{array}$ \\
\hline Sigmoid kernel function & $\begin{array}{c}\mathrm{K}(\mathrm{x}, \mathrm{y})=\tanh (\kappa\langle\mathrm{x}, \mathrm{y}\rangle+\mathrm{v}), \\
\kappa \geq 0, \mathrm{v} \geq 1\end{array}$ \\
\hline
\end{tabular}
model. By reading the literature, we can see that the definition of the kernel function given by different literatures is slightly different. According to the solution needs, this paper uses the method of literature [14] to define the kernel function. Table 1 lists some commonly used kernel functions:

Table 1 Commonly used kernel functions

According to the role of the kernel function in the drilling force prediction model and the characteristics of the Gaussian radial basis kernel function (a scalar function that is symmetric along the radial direction), this paper chooses the Gaussian radial basis kernel function when modeling.

(2) Loss function

Due to the high precision requirements of the drilling force modeling of the CFRP internal chip removal hole-making process, it is necessary to select a more suitable loss function. Table 2 lists some common loss functions.

Table 2 Commonly used loss functions

\begin{tabular}{cc}
\hline Loss functions & Formula \\
\hline $\begin{array}{c}\text { Laplace } \\
\text { Gauss }\end{array}$ & $\left|\xi_{\mathrm{i}}\right|_{\varepsilon}$ \\
Robust loss function & $\frac{1}{2}\left|\xi_{\mathrm{i}}\right|$ \\
Huber & $\left\{\begin{array}{cc}\frac{1}{2 \sigma}\left(\xi_{i}\right)^{2},\left|\xi_{i}\right| \leq \sigma \\
\left|\xi_{i}\right|-\sigma, & \text { other }\end{array}\right.$ \\
& $\left\{\begin{array}{cc}\frac{1}{2 \sigma}\left(\xi_{i}\right)^{2},\left|\xi_{i}\right| \leq \varepsilon \\
\varepsilon\left|\xi_{i}\right|-\frac{\varepsilon}{2}, & \text { other }\end{array}\right.$ \\
\hline
\end{tabular}

When using the loss functions in Table 2 and the support vector machine to model the drilling force of the internal chip removal hole-making process, it is necessary to introduce the slack variables $\xi=\left(\xi_{1}, \xi_{2}, \cdots, \xi_{n}\right)^{\mathrm{T}}, \quad \xi^{*}=\left(\xi_{1}^{*}, \xi_{2}^{*}, \cdots, \xi_{n}^{*},\right)^{\mathrm{T}}$ and introduce the constraint $f\left(x^{i}\right)-y^{i} \leq \xi_{1}, y^{i}-f\left(x^{i}\right) \leq$ 
$\xi_{i}^{*}, i=1,2, \cdots, n$, Then the loss of the sample point $\left(x^{i}, y^{i}\right)$ can be expressed as $c_{i}=\tilde{c}\left(\xi_{i}\right)+\tilde{c}\left(\zeta_{i}^{*}\right)$, where $\tilde{c}$ is the selected loss function.

When the other loss functions in Table 2 are used instead of the $\varepsilon$-insensitive loss function, the original problem of the support vector machine regression machine becomes formula (13).

$$
\begin{array}{ll}
\min \frac{1}{2}\|\omega\|^{2}+C \sum_{i=1}^{n}\left(\tilde{c}\left(\xi_{i}\right)+\tilde{c}\left(\xi_{i}^{*}\right)\right) & \\
\text { s.t. } f\left(x^{i}\right)-y^{i} \leq \xi_{i} & i=1,2, \cdots, n \\
y^{i}-f\left(x^{i}\right) \leq \xi_{i}^{*} & i=1,2, \cdots, n \\
\xi_{i} \geq 0, \xi_{i}^{*} \geq 0 & i=1,2, \cdots, n
\end{array}
$$

$\beta_{i} \leq C \frac{d \bar{c}\left(\xi_{i}^{*}\right)}{d\left(\xi_{i}^{*}\right)}=0, \quad i=1,2, \cdots, n$

$\xi_{i}^{(*)}=\inf \left\{\xi_{i}^{*} \mid C \frac{d \bar{c}\left(\xi_{i}^{*}\right)}{d\left(\xi_{i}^{*}\right)} \geq \alpha_{i}^{(*)}\right\}$

$\alpha_{i}^{(*)}, \xi_{i}^{(*)} \geq 0$

Where $T\left(\xi_{i}^{(*)}\right)=\tilde{c}\left(\xi_{i}^{(*)}\right)-\xi_{i}^{(*)} \frac{d \tilde{c}\left(\xi_{i}^{*}\right)}{d\left(\xi_{i}^{*}\right)}$.

As the Huber loss function is highly robust and insensitive to outliers, this paper chooses the Huber loss function for modeling analysis. The optimization model of the regression problem is thus formula (15)

$$
\begin{aligned}
& \min \frac{1}{2} \sum_{i,=1}^{n} \sum_{j=1}^{n}\left(\beta_{i}-\alpha_{i}\right)\left(\beta_{j}-\alpha_{j}\right) K\left\langle x^{i}, x^{j}\right\rangle \\
& -\sum_{i=1}^{n}\left(\beta_{i}-\alpha_{i}\right) y^{i}+\frac{\varepsilon}{2 C} \sum_{i=1}^{n}\left(\beta_{i}-\alpha_{i}\right)^{2} \\
& \text { s.t. } \sum_{i=1}^{n}\left(\alpha_{i}-\beta_{i}\right), \quad 0 \leq \beta_{i}, \alpha_{i} \leq C, \quad i, j=1,2, \cdots, n
\end{aligned}
$$

$\alpha_{\mathrm{i}}^{*}, \beta_{\mathrm{i}}^{*}$ is denoted as the optimal solutions of the above duality, and the regression function $\mathrm{f}(\mathrm{x})$ is still formula (12).

Based on the above theoretical research, this paper can establish a theoretical model for the relationship between tool parameters, cutting parameters, aspirating parameters and the drilling force for a certain type of the CFRP material holemaking process.

\section{CFRP drilling experiment}

The above contents give the theory of drilling force modeling for CFRP machining based on support vector regression, but to get the drilling force model of internal chip removal processing, the experiment of internal chip removal drilling is needed, so the drilling force experiment of CFRP chip removal is introduced below, the experimental results are given to complete the drilling force modeling.

\subsection{Experimental condition}

The CFRP used in the experiment was provided by Hafei Industrial Co., Ltd., with a thickness of $4.5 \mathrm{~mm}$. The processing equipment used in the experiment is a suction type internal chip removal system; The testing equipment used is Kistler 9171A rotary dynamometer, and the cutting force is transmitted to the computer through the data acquisition system and signal conditioner during operation. The experimental equipment configuration is shown in Figure 4.

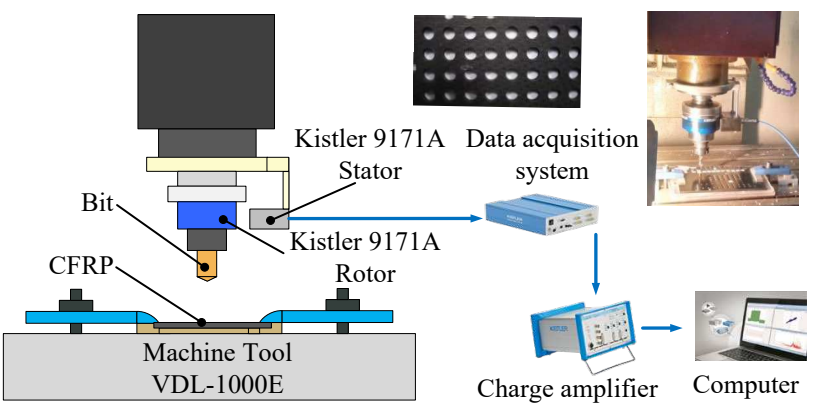

Fig.4 The experimental equipment configuration is shown

The aspirating internal chip drill bit used in the experiment is designed independently [19]. The design is based on the literature. This drill bit is manufactured by Guohong Tool System (Wuxi). The actual object is shown in Figure 5. The blade structure is shown in Figure 6. 18 drill bits were manufactured according to the experiment's requirements (see Table 3 for tool parameters). Ltd. During the experiment, each group of parameters was subjected to 3 replicate experiments, and the average was taken as the result.

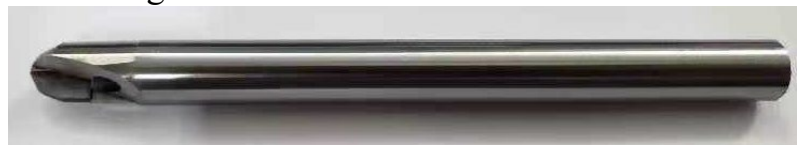

Fig.5 Aspirating internal chip drill bit

The PCD blade for the aspirating internal chip removal drill bit shown in Figure 6 adopts a double-edged structure, in which the function of the major cutting edge is to cut, the major and minor cutting edges' function is to ream and smoothen, and the minor cutting edge's function is to smoothen. The blade parameters shown in the figure: D-blade diameter, $\mathrm{a}_{1}$-point angle, $\mathrm{a}_{2}$-small point angle, $r$-chisel edge 
slope, $\mathrm{L}_{1}$-major cutting edge vertical length, $\mathrm{L}_{2}$-major and minor cutting edge vertical length, h-chisel edge length, $\lambda$ relief angle, and the specific parameter values are shown in Table 4

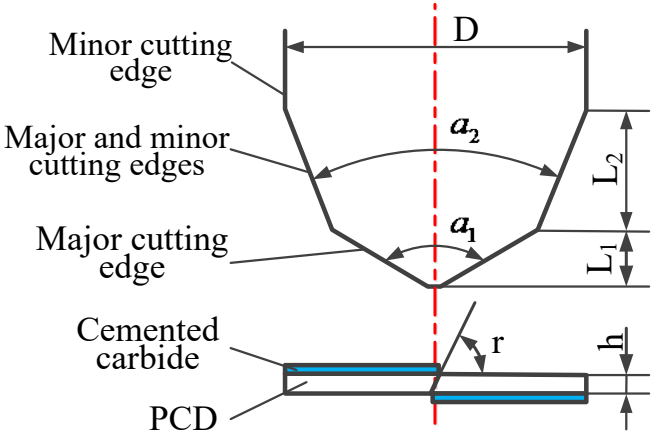

Fig.6 PCD double peak angle blade structure diagram

Table 3 Experiment blade parameters

\begin{tabular}{cc}
\hline Name & Numerical value \\
\hline $\mathrm{D} /(\mathrm{mm})$ & $6,8,10$ \\
$\mathrm{~h} /(\mathrm{mm})$ & 1.2
\end{tabular}
$\mathrm{a}_{1} /\left(^{\circ}\right)$
90、120、140
$\mathrm{a}_{2} /\left(^{\circ}\right)$
42
$\mathrm{r} /\left(^{\circ}\right)$
48
$\lambda /\left(^{\circ}\right)$
8、12、16

(Note: The ratio of the length of the major cutting edge to the minor cutting edge is $L_{1}: L_{2}=1: 1$.)

\subsection{Experiment results}

Using the above systems and tools, the CFRP internal chip removal hole drilling experiments under different cutting parameters (rotation speed, feed rate) and aspirating parameters (negative pressure) were carried out, and the obtained drilling force and torque results are shown in Table 3. (According to the analysis of the experimental results, we can know that: The quality of the holes obtained by the experiment meets the requirements of CFRP hole-making accuracy, because this paper mainly introduces the problem of drilling force modeling, therefore the results of the experimental pore-making quality are not elaborated.)

Table 4 CFRP drilling processing experiment results

\begin{tabular}{|c|c|c|c|c|c|c|c|c|}
\hline \multirow{3}{*}{ Factor } & \multicolumn{6}{|c|}{ Experimental parameters } & \multirow{2}{*}{\multicolumn{2}{|c|}{ Experimental result }} \\
\hline & \multirow[b]{2}{*}{$\begin{array}{c}\text { Drill } \\
\text { diameter } \\
(\mathrm{mm})\end{array}$} & \multirow{2}{*}{$\begin{array}{l}\text { Tool parameters } \\
\text { Point angle } \\
\text { ( ) }\end{array}$} & \multirow[b]{2}{*}{$\begin{array}{c}\text { Relief } \\
\text { angle } \\
\left(^{\circ}\right)\end{array}$} & \multirow{2}{*}{$\begin{array}{c}\text { Aspirating } \\
\text { parameters } \\
\text { Negative } \\
\text { pressure }(\mathrm{KPa})\end{array}$} & \multicolumn{2}{|c|}{ Cutting parameters } & & \\
\hline & & & & & $\begin{array}{l}\text { Rotation } \\
\text { speed } \\
(\mathrm{r} / \mathrm{min})\end{array}$ & $\begin{array}{l}\text { Feed rate } \\
(\mathrm{mm} / \mathrm{min})\end{array}$ & $\begin{array}{l}\text { Drilling } \\
\text { force } \\
(\mathrm{N})\end{array}$ & $\begin{array}{l}\text { Torque } \\
(\mathrm{N} \cdot \mathrm{m})\end{array}$ \\
\hline 1 & 6 & 90 & 8 & 9 & 3000 & 50 & 102.96 & 0.43 \\
\hline 2 & 6 & 120 & 12 & 12 & 4000 & 150 & 99.54 & 0.36 \\
\hline 3 & 6 & 140 & 16 & 15 & 5000 & 260 & 90.65 & 0.42 \\
\hline 4 & 8 & 90 & 8 & 15 & 4000 & 150 & 104.03 & 0.38 \\
\hline 5 & 8 & 120 & 12 & 9 & 5000 & 260 & 107.72 & 0.34 \\
\hline 6 & 8 & 140 & 16 & 12 & 3000 & 50 & 144.45 & 0.38 \\
\hline 7 & 10 & 90 & 12 & 12 & 3000 & 260 & 128.60 & 0.51 \\
\hline 8 & 10 & 120 & 16 & 15 & 4000 & 50 & 108.95 & 0.37 \\
\hline 9 & 10 & 140 & 8 & 9 & 5000 & 150 & 118.06 & 0.42 \\
\hline 10 & 6 & 90 & 16 & 12 & 5000 & 150 & 72.99 & 0.37 \\
\hline 11 & 6 & 120 & 8 & 15 & 3000 & 260 & 113.02 & 0.39 \\
\hline 12 & 6 & 140 & 12 & 9 & 4000 & 50 & 95.81 & 0.32 \\
\hline 13 & 8 & 90 & 12 & 15 & 5000 & 50 & 79.04 & 0.39 \\
\hline 14 & 8 & 120 & 16 & 9 & 3000 & 150 & 116.00 & 0.41 \\
\hline 15 & 8 & 140 & 8 & 12 & 4000 & 260 & 124.20 & 0.39 \\
\hline 16 & 10 & 90 & 16 & 1.4 & 4000 & 26 & 103.43 & 0.37 \\
\hline 17 & 10 & 120 & 8 & 1.6 & 5000 & 50 & 106.15 & 0.40 \\
\hline 18 & 10 & 140 & 12 & 1.8 & 3000 & 150 & 138.60 & 0.44 \\
\hline
\end{tabular}




\section{Construction of Drilling Force Prediction Model}

\subsection{Forecast model accuracy analysis}

Based on the limited experiment data and on the above theoretical analyses, we used Platt's SMO algorithm and the support vector machine to model the drilling force of the CFRP internal chip removal hole-making process. To illustrate the accuracy of the model that has been established, the accuracy analyses before the resolution were done for the following two problems to be modeled in the following paragraphs.

Model1: The tool parameters (drill diameter, peak angle, relief angle), aspirating parameters (negative pressure) and cutting parameters (cutting speed, feed rate) are independent variables, and the axial force is used as the dependent variable to establish the relationship model.( Note: The axial force in the prediction model is the maximum axial force generated during drilling. Because the axial force in CFRP hole making is the main reason that affects hole making defects and tool wear, effectively controlling the maximum axial force generated during machining can effectively inhibit the occurrence of defects and reduce tool wear speed.)

Model 2: The tool parameters (drill diameter, peak angle, relief angle), aspirating parameters (negative pressure), and cutting parameters (cutting speed, feed rate) are independent variables, and the torque is used as the dependent variable to establish the relationship model.

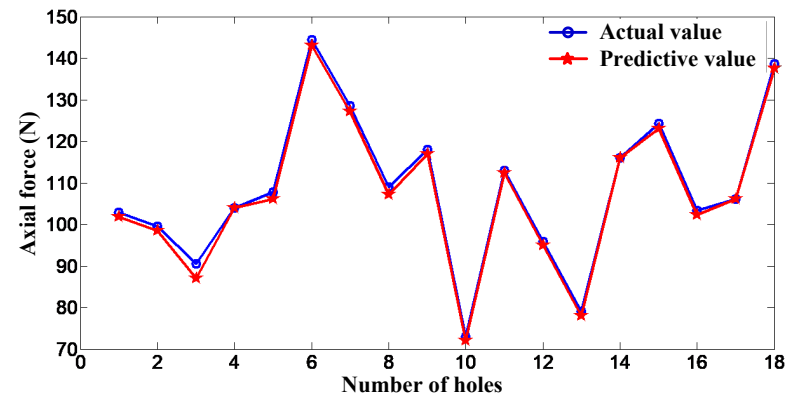

Fig.7 Sample fitting results of model 1

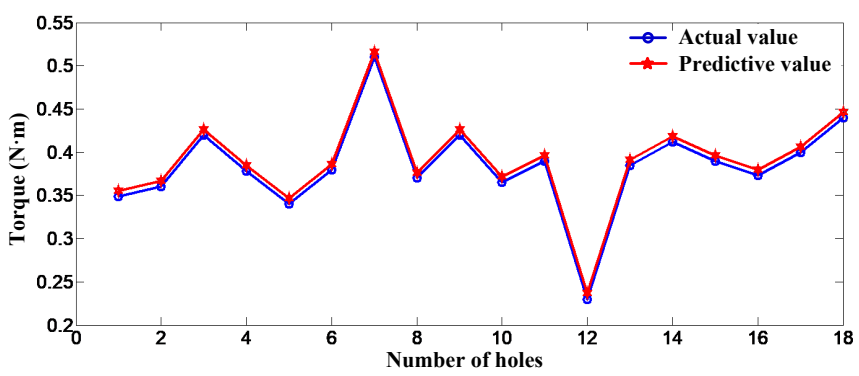

Fig.8 Sample fitting results of model 2
Figure 7 and Figure 8 are diagrams showing the fitting effect of the relational model obtained by solving the above two problems with to the sample data in Table 4.

From the analysis of simulation results in Fig. 7 and Fig. 8, it can be seen that the drilling force prediction model constructed according to the theory and solution algorithm of this paper has very little error with the sample data, that is, the accuracy of the built prediction model meets the modeling requirements of this paper.

Table 5 shows the penalty function value and the fitting accuracy of the relationship model and the optimal solution fitness function value when constructing model 1 and model 2 based on the support vector regression machine theory.

Table 5 Simulation experiment parameter values, fitting accuracy and fitness values

\begin{tabular}{ccccc}
\hline \multirow{2}{*}{ Model } & \multirow{4}{c}{ F } & Mitting accuracy & \multirow{2}{*}{ Fitness values } \\
& & MSE & RNew & \\
\hline Model 1 & 30 & 0.0675 & 0.8991 & -1.8498 \\
Model 2 & 45 & 0.0703 & 0.8975 & -2.0965 \\
\hline
\end{tabular}

Through the analysis of Table 5 , it can be seen that the drilling force prediction model established by the theory described in this article has high mean square error and fitting accuracy, that is, the accuracy of the constructed model meets the requirements.

\subsection{Prediction model of drilling force for internal chip removal processing}

The accuracy analysis of the drilling force prediction model is completed above, and the expression and correlation coefficient values of the prediction model are given below to complete the construction of the drilling force prediction model for internal chip removal processing.

Based on the experimental data in Table 4, based on the theory of support vector regression, using the SMO solution algorithm and penalty function value, the construction of the CFRP internal chip removal processing drilling force prediction model is completed. The constructed drilling force prediction model is shown in formula (16).

For the convenience of analysis, when solving, Let $\mathrm{x}=$ $\left(\mathrm{x}_{1}, \mathrm{x}_{2}, \mathrm{x}_{3}, \mathrm{x}_{4}, \mathrm{x}_{5}, \mathrm{x}_{6}\right)$ be the independent variables, $\mathrm{x}_{1}, \mathrm{x}_{2}, \mathrm{x}_{3}, \mathrm{x}_{4}, \mathrm{x}_{5}, \mathrm{x}_{6} \in \mathrm{R}$ represent the drill bit diameter, the point angle, the length of the chisel edge, the negative pressure, the rotational speed and the feed rate. Let $\mathrm{z}_{1}, \mathrm{z}_{2}, \mathrm{z}_{3}, \mathrm{z}_{4}, \mathrm{z}_{5}, \mathrm{z}_{6}$ be the data set to be applied when solving the regression model, i.e. the values of the tool parameters, aspirating parameters and processing parameters used in the experiments. 


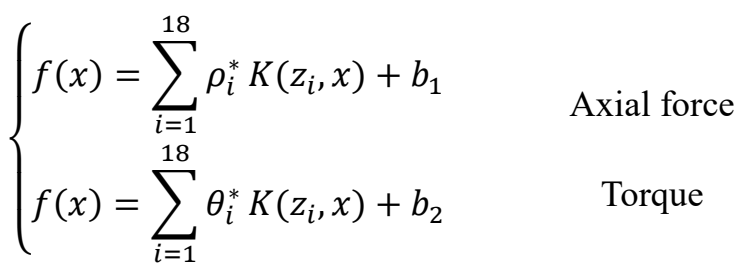

At the same time, the coefficient values in model (16) can be solved, as shown in Table 6 .

Table 6 Coefficient values in the model

\begin{tabular}{cccc}
\hline Variable & Value & Variable & Value \\
\hline$\rho_{1}^{*}$ & -7.8532 & $\theta_{1}^{*}$ & -1.4364 \\
$\rho_{2}^{*}$ & -11.2680 & $\theta_{2}^{*}$ & -1.4254 \\
$\rho_{3}^{*}$ & -20.1445 & $\theta_{3}^{*}$ & -1.3655 \\
$\rho_{4}^{*}$ & -6.7848 & $\theta_{4}^{*}$ & -1.4075 \\
$\rho_{5}^{*}$ & -3.1004 & $\theta_{5}^{*}$ & -1.4454 \\
$\rho_{6}^{*}$ & 33.5738 & $\theta_{6}^{*}$ & -1.4055 \\
$\rho_{7}^{*}$ & 17.7479 & $\theta_{7}^{*}$ & -1.2757 \\
$\rho_{8}^{*}$ & -1.8722 & $\theta_{8}^{*}$ & -1.4154 \\
$\rho_{9}^{*}$ & 7.2239 & $\theta_{9}^{*}$ & -1.3655 \\
$\rho_{10}^{*}$ & -33.9988 & $\theta_{10}^{*}$ & -1.4204 \\
$\rho_{11}^{*}$ & 2.1916 & $\theta_{11}^{*}$ & -1.3955 \\
$\rho_{12}^{*}$ & -28.5517 & $\theta_{12}^{*}$ & -1.5552 \\
$\rho_{13}^{*}$ & -31.7368 & $\theta_{13}^{*}$ & -1.4005 \\
$\rho_{14}^{*}$ & 5.1670 & $\theta_{14}^{*}$ & -1.3735 \\
$\rho_{15}^{*}$ & 13.3546 & $\theta_{15}^{*}$ & -1.3955 \\
$\rho_{16}^{*}$ & -7.3938 & $\theta_{16}^{*}$ & -1.4125 \\
$\rho_{17}^{*}$ & -4.6680 & $\theta_{17}^{*}$ & -1.3855 \\
$\rho_{18}^{*}$ & 27.7327 & $\theta_{18}^{*}$ & -1.3456 \\
$\mathrm{~b}_{1}$ & 0.00254 & $\mathrm{~b}_{2}$ & 0.3359 \\
\hline
\end{tabular}

\section{Prediction study on factors influencing axial force}

According to the analysis of existing research results, in CFRP hole making, axial force is the main cause of delamination defects and tool wear. Therefore, the above model established will be applied to predict the relationship between the tool parameters, the aspirating parameters, the cutting parameters and the axial force to provide a reference for the subsequent selection of the process parameters of the CFRP internal chip removal hole-making process.

\subsection{Prediction of the influence of the cutting parameters}

(1) Prediction of the influence of feed rate on axial force

Under the conditions of the rotation speed of $3000 \mathrm{r} / \mathrm{min}$, the diameter of the drill bit of $8 \mathrm{~mm}$, the relief angle of $12^{\circ}$, the point angle of $130^{\circ}$ and the negative pressure of $9 \mathrm{KPa}$, the relationship between the feed rate and the axial force is predicted by the above model. The obtained curve of the change of the axial force versus the feed rate is shown in
Figure 9.

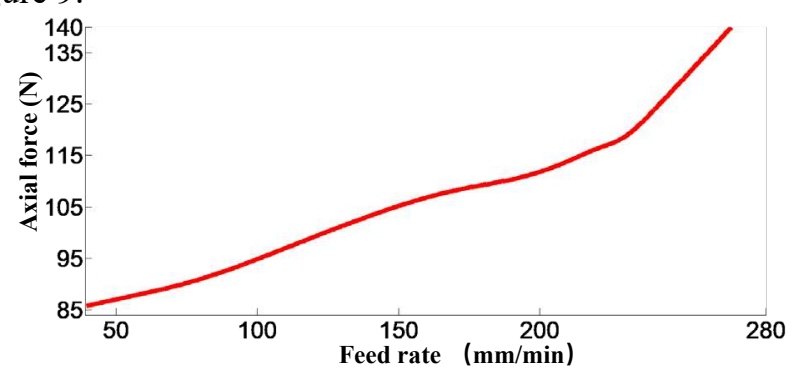

Fig.9 The curve of the change of the axial force versus the feed rate

From the analysis of the prediction results obtained in Figure 9, it can be seen that when the feed rate gradually increases, the axial force is also increasing. Comparing the above prediction results with the research conclusions of the existing researchers, it can be seen that the change of the axial force with the feed rate predicted by this model is consistent with the research conclusions of the existing researchers, which further explains the predictions built in this article. The correctness of the model. Analyze the reasons for the above phenomenon: When the feed rate increases, the mass of the material removed by the drill bit in the unit time increases, so the axial force increases. Further analysis with reference to the above prediction results shows that: In order to meet the drilling processing requirements, when drilling, you can choose the feed rate that produces a smaller axial force during the prediction as the cutting parameters during hole making. That is, when drilling under the above parameters, you can choose to enter The range of feeding amount is $50 \mathrm{~mm} / \mathrm{min}$ to $200 \mathrm{~mm} / \mathrm{min}$.

\section{(2) Prediction of the effect of rotational speed on axial force}

Under the conditions of the feed rate of $200 \mathrm{~mm} / \mathrm{min}$, the diameter of the drill bit of $8 \mathrm{~mm}$, the relief angle of $12^{\circ}$, the point angle of $130^{\circ}$ and the negative pressure of $9 \mathrm{KPa}$, the relationship between the rotational speed and the axial force is predicted by the above model. The curve of the change of the axial force obtained versus the rotational speed is shown in Figure 10.

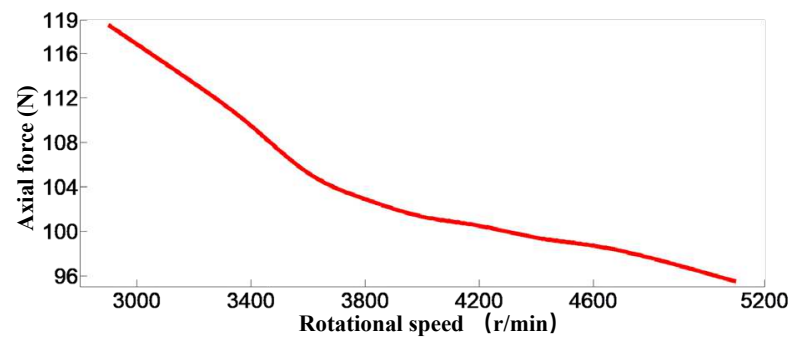

Fig.10 The curve of the change of the axial force versus the rotational speed

From the analysis of the prediction results obtained in Fig. 
10 , it can be seen that as the speed increases, the axial force shows a downward trend. Comparing the above prediction results with the research conclusions of the existing researchers, it can be seen that the change of the axial force with the rotation speed predicted by this model is consistent with the research conclusions of the existing researchers, which further illustrates the prediction model built in this paper. Correctness. Analyze the reasons for the above phenomenon: when the cutting speed increases, the cutting heat generated by the cutting process will increase, which will cause the CFRP material matrix to soften, which will lead to the reduction of the axial force in the cutting process. Further analysis with reference to the above prediction results shows that: in order to meet the drilling requirements, when drilling, you can choose the speed that produces a smaller axial force during the prediction as the cutting parameters during hole making, that is, drilling under the above parameters During processing, the range of feed can be selected from $3000 \mathrm{r} / \mathrm{min}$ to $5000 \mathrm{r} / \mathrm{min}$.

Comparing and analyzing the prediction results of feed and speed on the axial force, it can be seen that the influence of feed on the axial force is much greater than the influence of speed on the axial force when making holes in CFRP material.

\subsection{Prediction of the influence of cutting tool parameters on axial force}

(1) Prediction of the influence of the point angle on the axial force

Under the conditions of the rotational speed of $3000 \mathrm{r} / \mathrm{min}$, the feed rate of $200 \mathrm{~mm} / \mathrm{min}$, the drill bit diameter of $8 \mathrm{~mm}$, the relief angle of $12^{\circ}$ and the negative pressure of $9 \mathrm{KPa}$, the relationship between the point angle of the drill bit and the axial force is predicted by the above model. The curve of the change of the axial force obtained versus the point angle of the drill bit is shown in Figure 11.

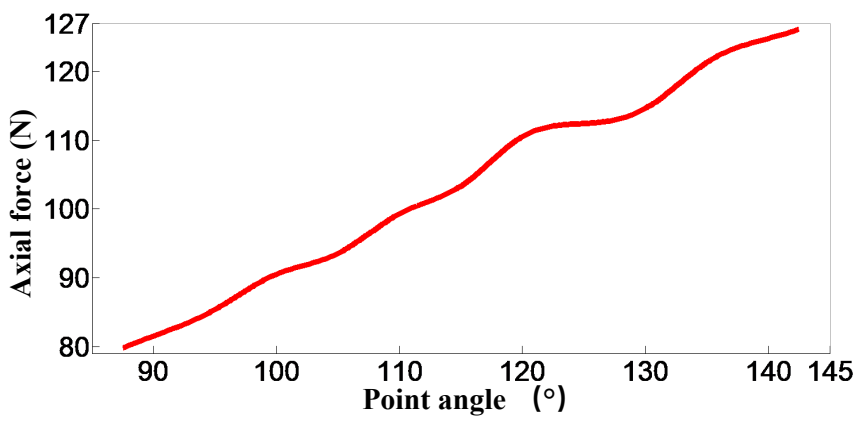

Fig.11 The curve of the change of the axial force versus the point angle

From the analysis of the prediction results obtained in Figure 11, it can be seen that with the increase of the point angle, the axial force generally increases. Through further analysis, it can be seen that when the point angle is in the range of $120^{\circ} \sim 135^{\circ}$, the axial force increases with the increase of the point angle is not obvious. Comparing the above prediction results with the experimental results obtained in this paper, we can see that the change of the axial force with the point angle predicted by this model is consistent with the experimental conclusions. Analyze the reasons for the above phenomenon: when the front angle increases, the entering angle will increase, and when the entering angle increases, the length of the cutting edge involved in cutting per unit time increases, resulting in an increase in the axial force. And when the front angle increases, the chisel edge oblique angle will decrease, that is, the chisel edge length will increase, which will also cause the axial force to increase. Further analysis with reference to the above prediction results shows that: in order to meet the drilling processing requirements, when designing the drill bit, the point angle that produces a smaller axial force change trend during the prediction can be selected as the bit design parameter, that is, when the drill bit is designed, the point angle can be selected. The angular range is from $120^{\circ}$ to $135^{\circ}$.

(2) Prediction of the influence of the relief angle on the axial force

Under the conditions of the rotation speed of $3000 \mathrm{r} / \mathrm{min}$, the feed rate of $200 \mathrm{~mm} / \mathrm{min}$, the drill bit diameter of $8 \mathrm{~mm}$, the point angle of $130^{\circ}$ and the negative pressure of $9 \mathrm{KPa}$, the relationship between the chisel edge and the axial force is predicted by the above model, and the curve of the change of the axial force obtained versus the relief angle of the drill bit is shown in Figure 12.

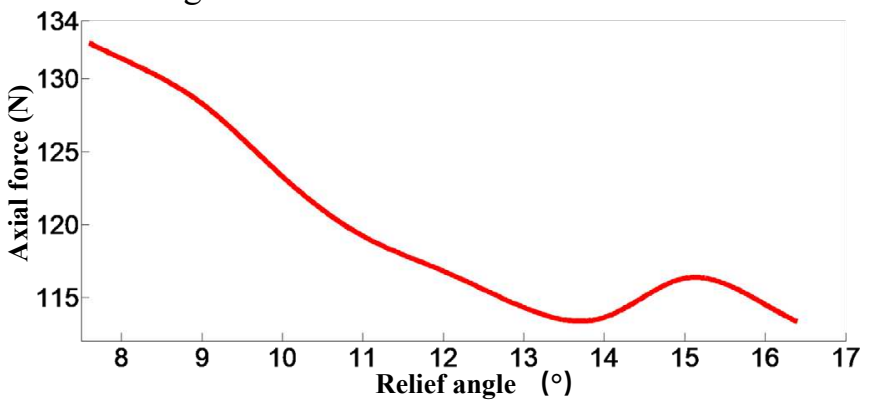

Fig.12 The curve of the change of the axial force versus the relief angle

From the analysis of the prediction results obtained in Figure 12, it can be seen that when the relief angle is less than $14^{\circ}$, as the relief angle increases, the axial force tends to decrease; When the relief angle is greater than $14^{\circ}$, as the relief angle increases, the axial force fluctuates (the fluctuation value is small). Analyze the reasons for the above 
phenomenon: the increase of the relief angle will lead to the reduction of the squeezing friction between the flank face of the drill and the material to be cut during the hole making process, which will lead to the reduction of the axial force. Further analysis with reference to the above prediction results shows that: in order to meet the drilling processing requirements, when designing the drill bit, you can select the relief angle that produces a smaller axial force during the prediction as the drill design parameter, that is, when designing the drill bit, you can select the relief angle angle It is $12^{\circ} \sim 14^{\circ}$

\subsection{Prediction of the influence of suction parameters on axial force}

Under the conditions of the rotation speed of $3000 \mathrm{r} / \mathrm{min}$, the feed rate of $200 \mathrm{~mm} / \mathrm{min}$, the drill bit diameter of $8 \mathrm{~mm}$, the point angle of $130^{\circ}$ and the length of the relief angle of $12^{\circ}$, the relationship between the negative pressure and the axial force is predicted by the above model, and the curve of the change of the axial force obtained versus the drilling negative pressure is shown in Figure 13.

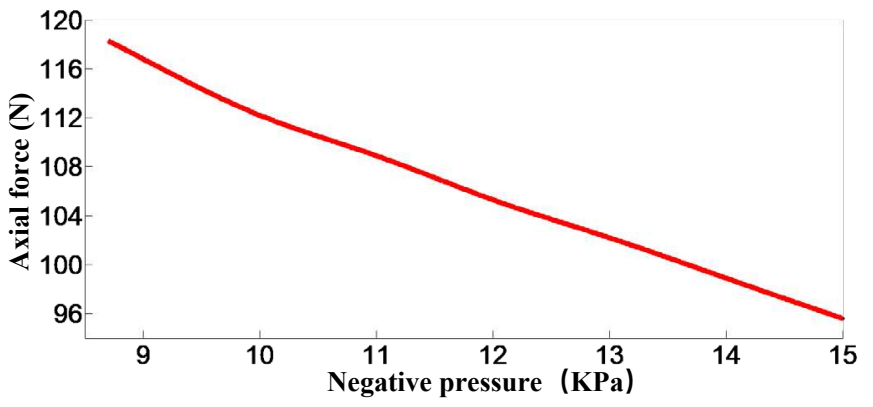

Fig.13 The curve of the change of the axial force versus the drilling negative pressure

From the analyses of the prediction results in Figure 13, it can be seen that as the negative pressure increases, the drilling force shows a downward trend. The reasons for the above phenomena are analyzed as follows: When the internal chip removal hole processing is performed, the direction of the drilling force generated by the drill bit hole machining is downward along the axis of the drill bit; the direction of the chip aspirating force generated by the aspirating chip negative pressure is upward along the axis. The axial force measured in the experiment is the resultant force of the two forces above. It can thus be deduced that as the negative pressure increases, the axial force generally decreases.

\section{Conclusions}

(1) Based on the application of support vector regression in data analysis, on the basis of selecting the appropriate kernel function and damage function, completed the research on the construction theory of the drilling force prediction model for CFRP internal chip removal processing;

(2) On the basis of obtaining the data set required for constructing the drilling force prediction model through experiments, and applying the theory and solution algorithm described in this article, the establishment of the drilling force prediction model for internal chip removal hole machining is completed. And the accuracy analysis of the internal chip removal machining drilling force prediction model is carried out to prove that the accuracy of the built model meets the requirements;

(3) Using the constructed internal chip removal hole machining drilling force prediction model, the influence of cutting parameters, tool parameters and suction parameters on the axial force is predicted and studied, providing a theory for the internal chip removal drill design and the selection of system process parameters in accordance with.

Funding information Thanks to The National Defense Science and Technology Innovation Special Zone Fund Project(208052020162) And the National Natural Science Foundation Project (51475127) supports the research of this subject.

Author Contributions Theoretical analysis and model construction were completed by Xu ChengYang and Wang YiWen, The experimental design and analysis were completed by $\mathrm{Xu}$ ChengYang and Wang GongDong, The thesis was written by $\mathrm{Xu}$ ChengYang and Yao SongYang, the supervision and optimization of the paper were completed by Wang YiWen and Xu JiaZhong.

Data availability All data generated or analyzed during this study are included in this published article.

\section{Compliance with ethical standards}

Competing interests The authors declare that they have no conflict of interest.

Ethical approval Not applicable

Consent to participate Not applicable

Consent to publish The authors consent to publish this article

\section{References}

1. Girot F, Dau F, Esther M, Orrantia G (2017) New analytical model for delamination of CFRP during drilling. J Mater Process Tech 240: $332-343$ 
2. Wang FJ, Qian BW, Jia ZY, Fu R, Cheng D (2017) Secondary cutting edge wear of one-shot drill bit in drilling CFRP and its impact on hole quality. Compos Struct 15(178): 341-352

3. Hocheng H, Dharan CKH (1990) Delamination during drilling in composite laminates. Journal of Engineering for Industry 112(3): 236-239

4. Chandrasekharan V, Kapoor SG, Devor RE (1995) A Mechanistic Approach to Predicting the Cutting Forces in Drilling: With Application to Fiber-Reinforced Composite Materials. Journal of Engineering for Industry 117(4): 559-570

5. Sun LH, Quan YM Zhong WW (2005) Study on High-speed Drilling Force for Carbon Fiber Composites. Fiber Composites 30(4): 30-38

6. Tsao CC, Hocheng H (2008) Evaluation of thrust force and surface roughness in drilling composite material using Taguchi analysis and neural network. J Mater Process Tech 203(1-3): 342-348

7. Ren SN, Wu D, Chen K (2013) Thrust force on the main cutting edge when cutting caibon fiber reinforced plastics. J Tsinghua Univ 53(4): 487-492

8. Hu LX (2016) Research on carbon fiber reinforced plastic-titanium alloy laminated plate drilling mechanism and technology. Hunan University of Science and Technology

9. Liu SN, Qi ZC, LI Y, Li Y, Meng QX (2017) On full life-cycle instantaneous force predicting when drilling CFRP-metal stacks. Int J Adv Manuf Techno 88(1-4): 651-661

10. Meng QX, Jiang XS, LIU SN, Zhang KF, Yan XH (2018) Study of thrust force distribution in a drilling cycle during drilling of CFRP laminates. Chin J Mech Eng-EN 54(11): 110-120

11. Jia ZY, Zhang C, Wang FJ, Fu R (2020) A mechanistic prediction model for thrust force and torque during drilling of CFRP/Ti stacks. Int J Adv Manuf Technol 106:3105-3115

12. Yan XY, Zhang KF, Cheng H, Luo B, Hou GY (2018) Force coefficient prediction for drilling of UD-CFRP based on FEM simulation of orthogonal cutting. Int J Adv Manuf Technol 97: $857-865$

13. Dandekar CR, Shin YC (2012) Modeling of machining of composite materials: A review. Int J Mach Tool Manu 57: 102-121

14. Deng NY, Tian YJ (2004) A New Method of Data Mining-Support Vector Machines. Science Press

15. Langella A, Nele L, Maio A (2005) A torque and thrust prediction model for drilling of composite materials. Compos Part A-Appl S 36(1): 83-93

16. Kisi, Ozgur (2015) Pan evaporation modeling using least square support vector machine, multi-variate adaptive regression splines and M5 model tree. J Hydrol 528: 312-320

17. Yao P, Xue JX, Zhou K (2015) Study on the wire feed speed prediction of double-wire-pulsed MIG welding based on support vector machine regression. Int J Adv Manuf Technol 79: 21072226

18. Barletta M, Pezzola S, Tagliaferri V, Trovalusci F, Vesco S (2013) Wear response and mechanical behaviour of silicone based photoluminescent coatings. Colloid Surface A 429: 1-11

19. Xu CY, Wang YW, Xu JZ, Liu XL (2018) Calculation of negativepressure chip in suction-type internal chip removal system and analysis of influencing factors. Int J Adv Manuf Technol 99(14): 201-209

20. Bernhard S, Smila AJ (2001) Learning with Kernels. The MIT press 


\section{Figures}

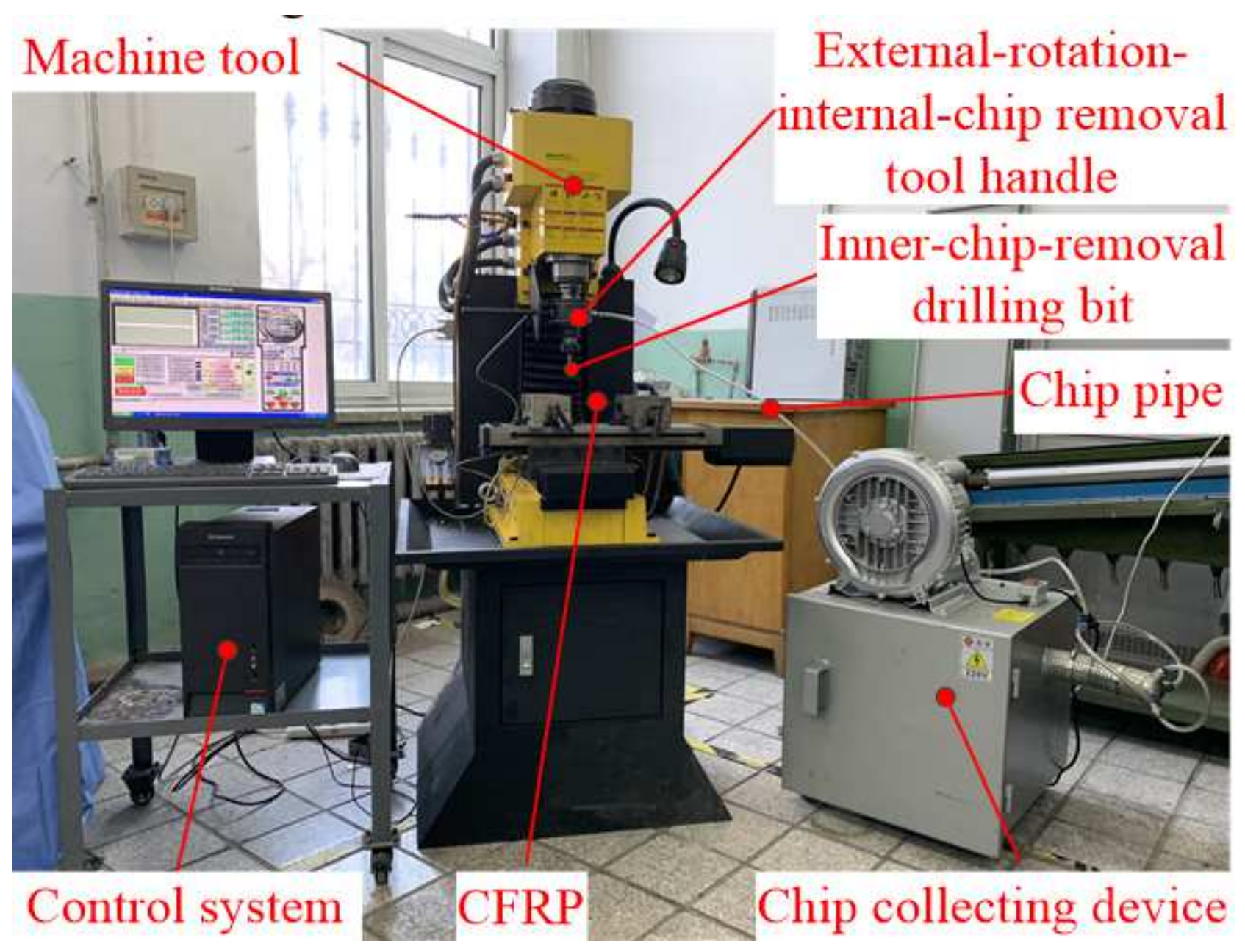

Figure 1

The Suction-type internal chip removal system 


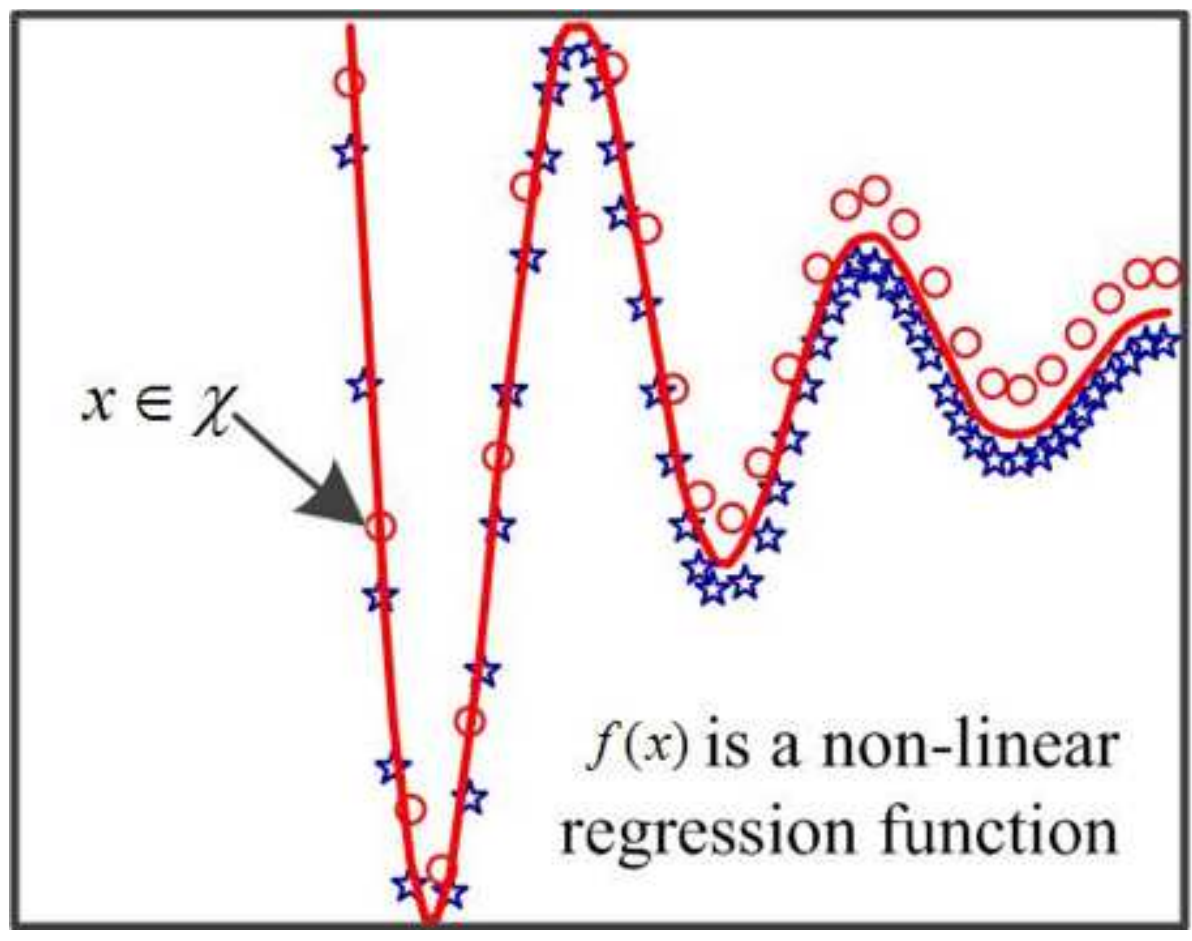

Figure 2

Nonlinear regression of data in oriinal input space $x$

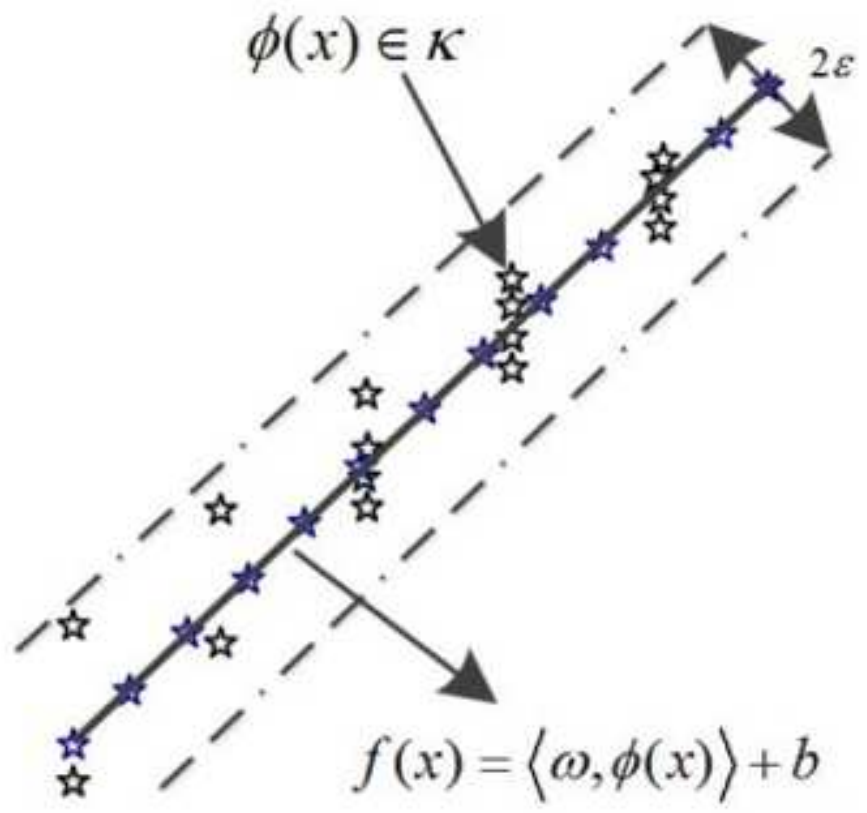

Figure 3

Linear regression of data in high dimensional characteristic space $\mathrm{\kappa}$ obtained by special mapping $\nabla$ 


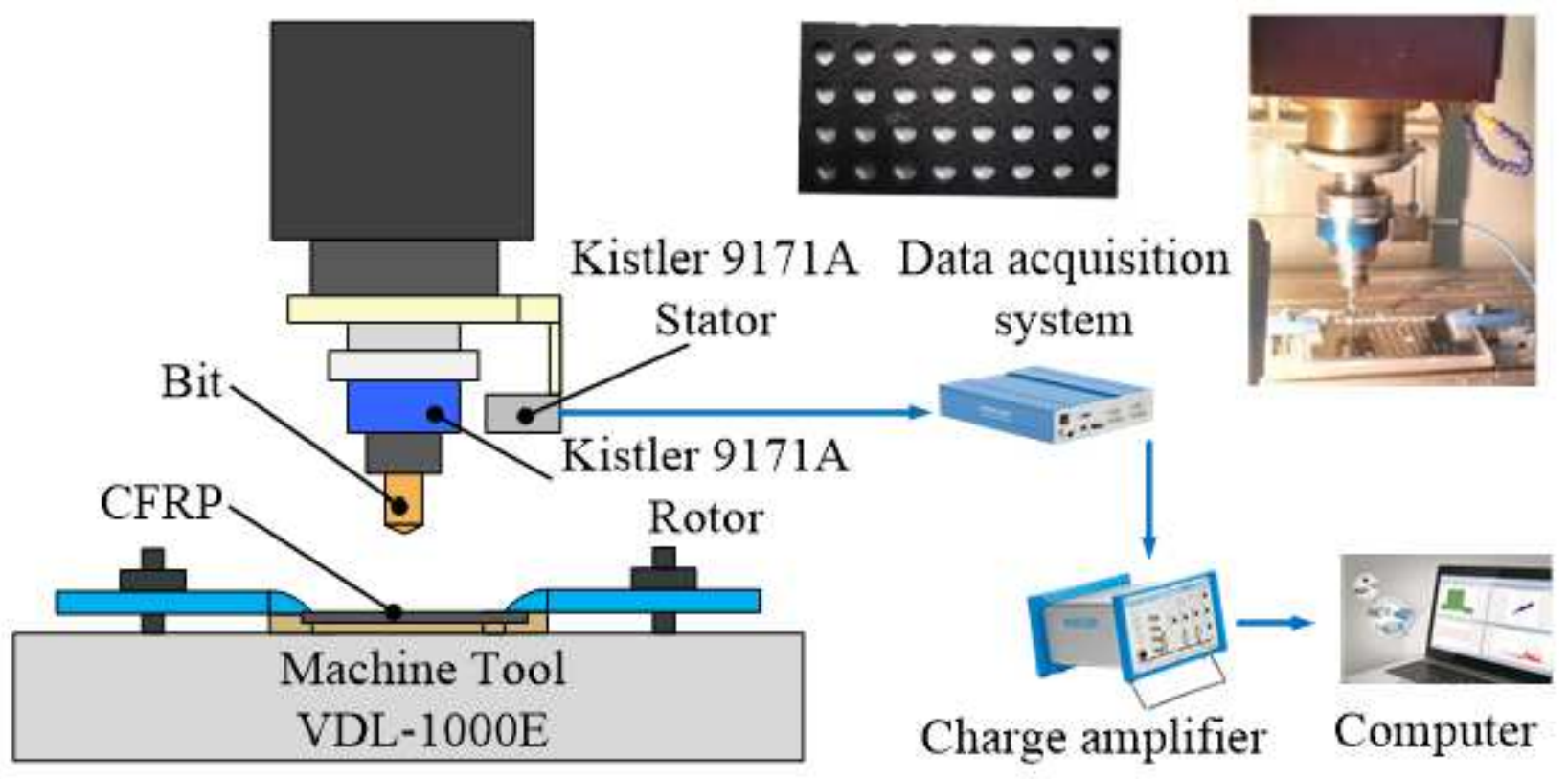

Figure 4

The experimental equipment configuration is shown

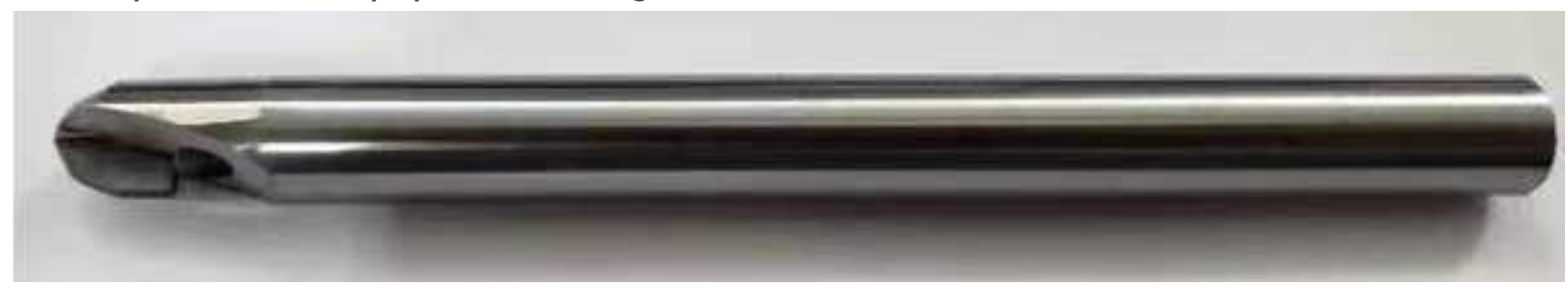

Figure 5

Aspirating internal chip drill bit

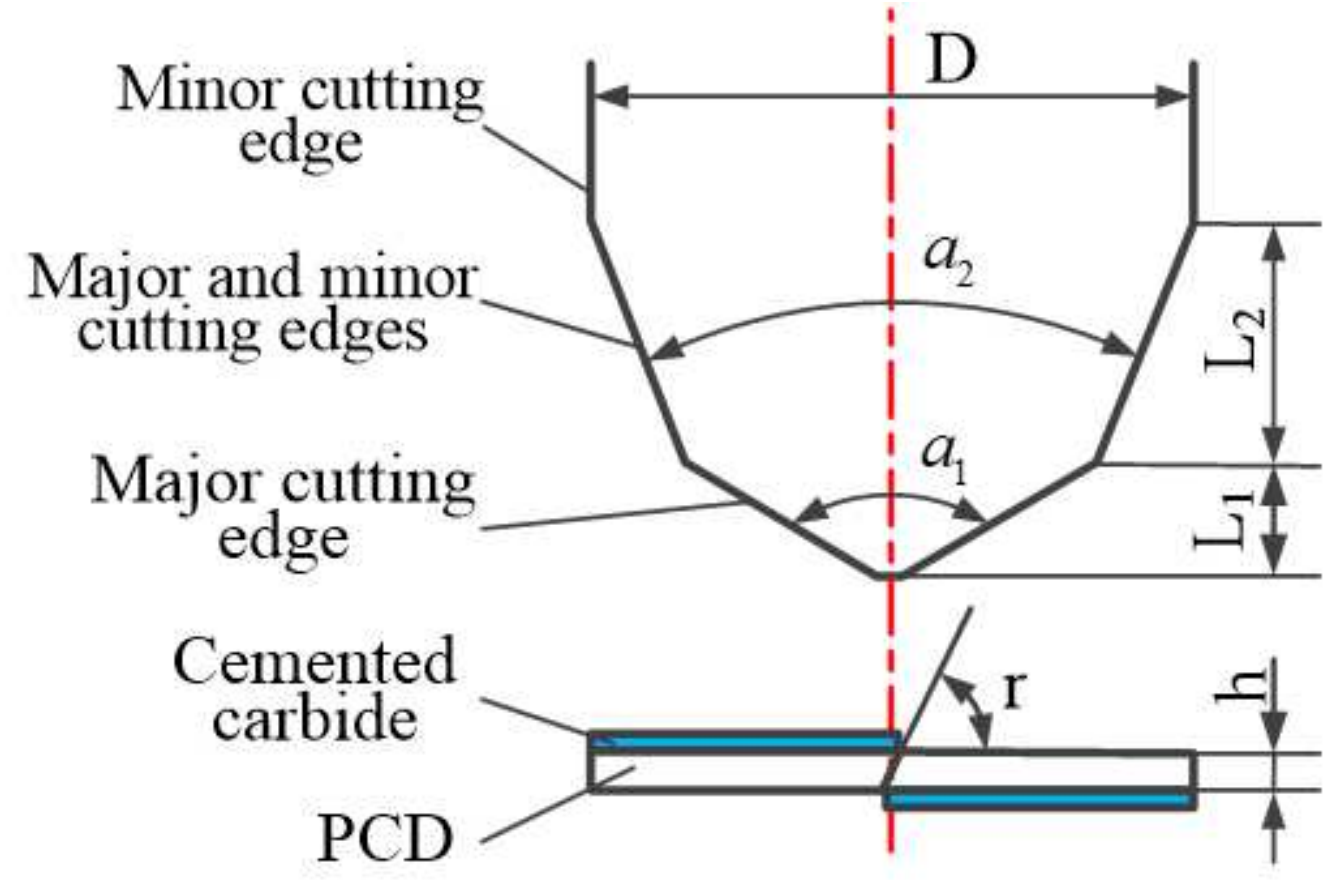


Figure 6

PCD double peak angle blade structure diagram

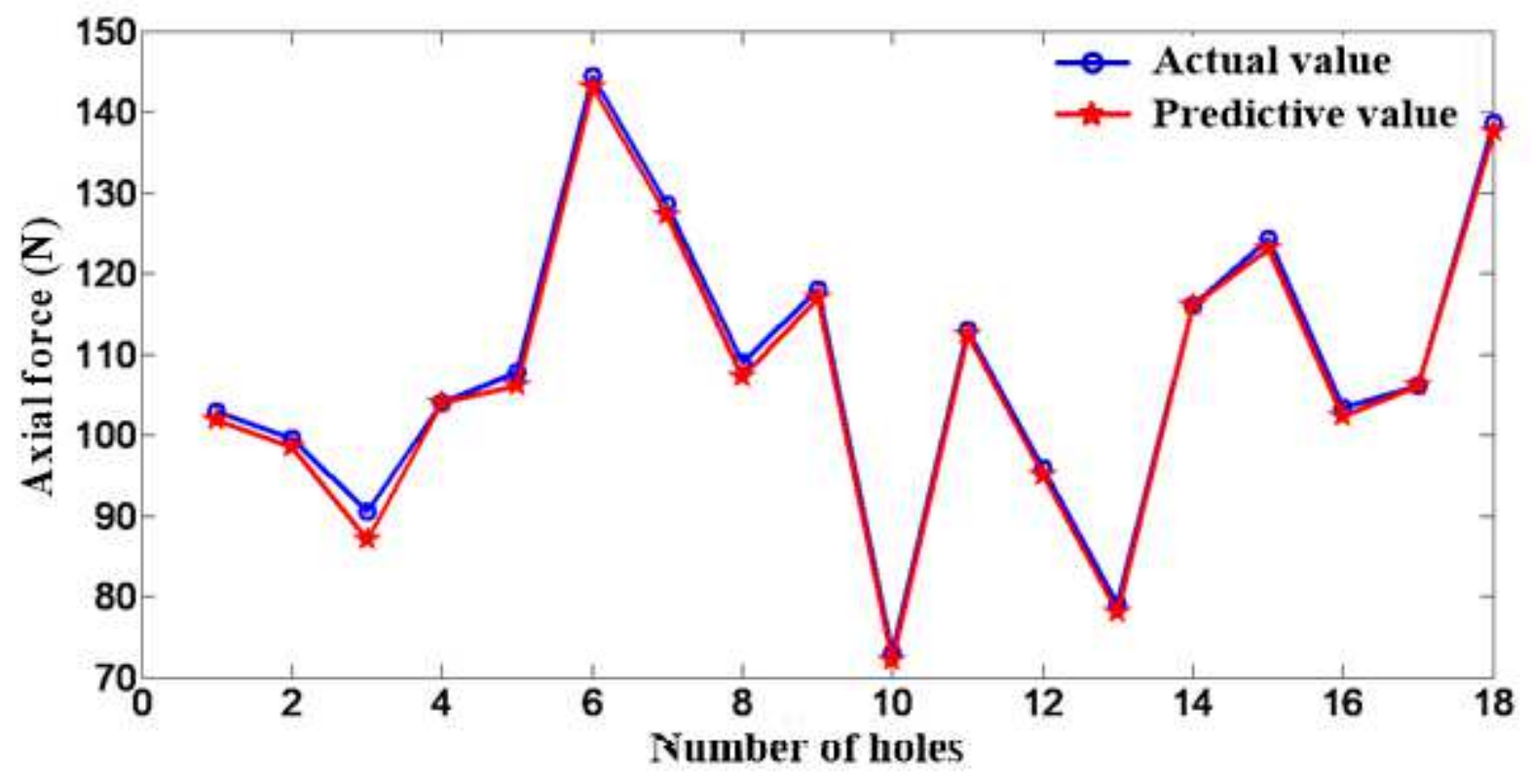

Figure 7

Sample fitting results of model 1

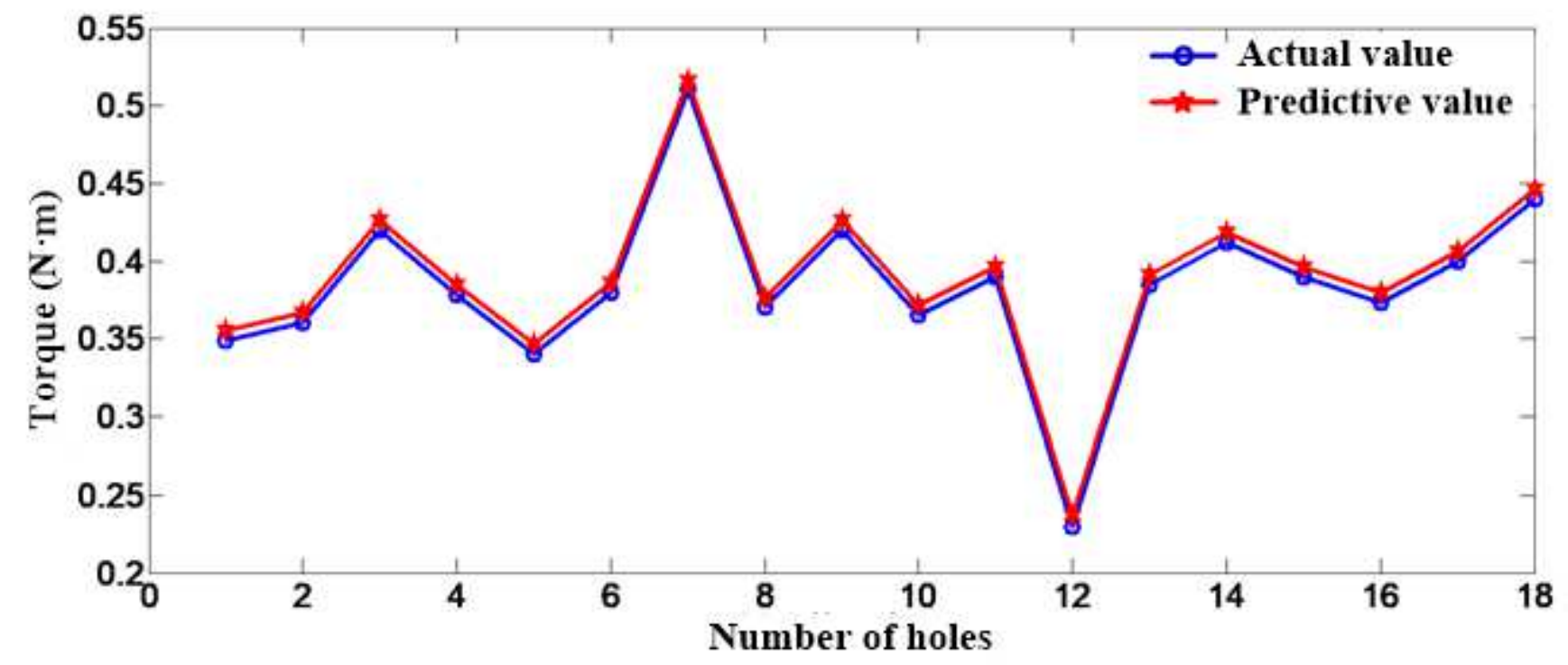

Figure 8

Sample fitting results of model 2 


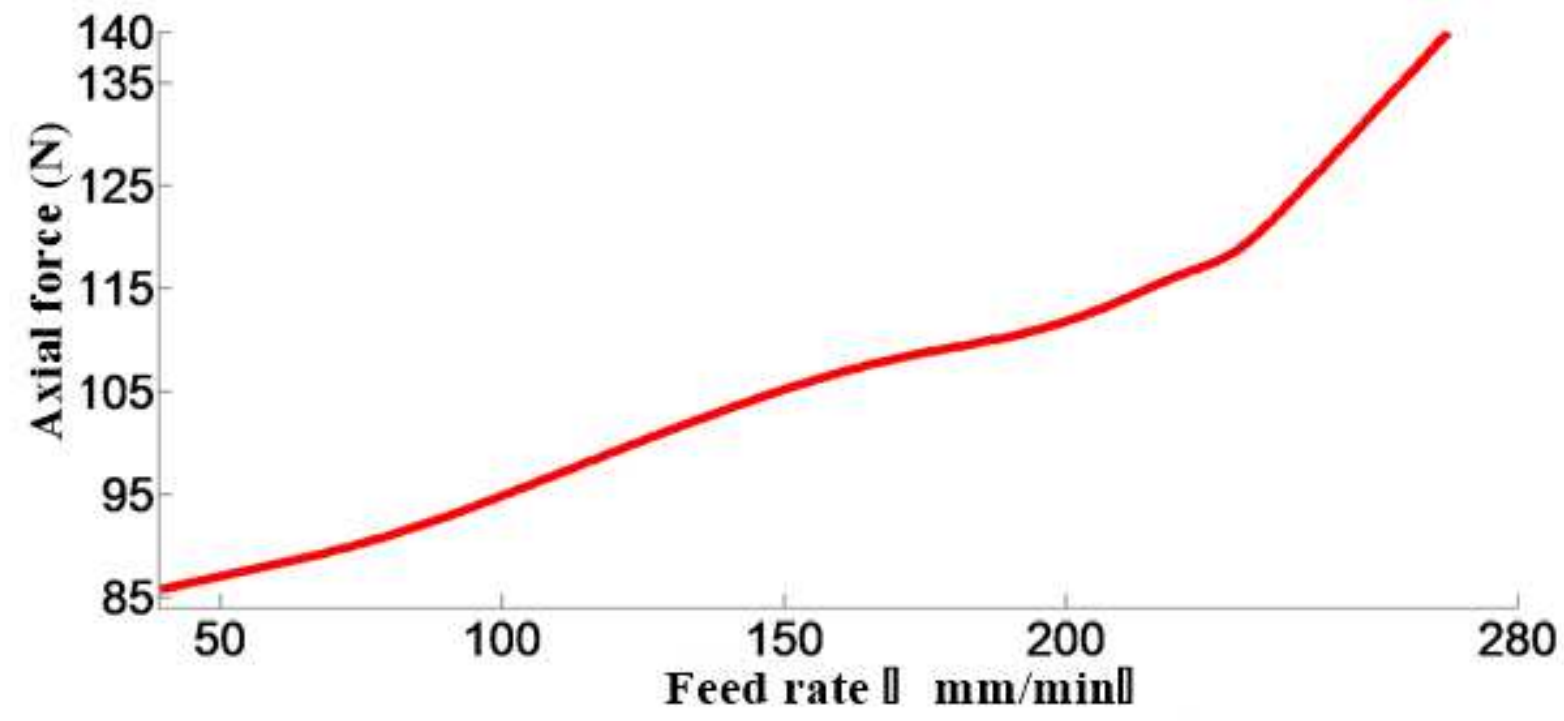

Figure 9

The curve of the change of the axial force versus the feed rate

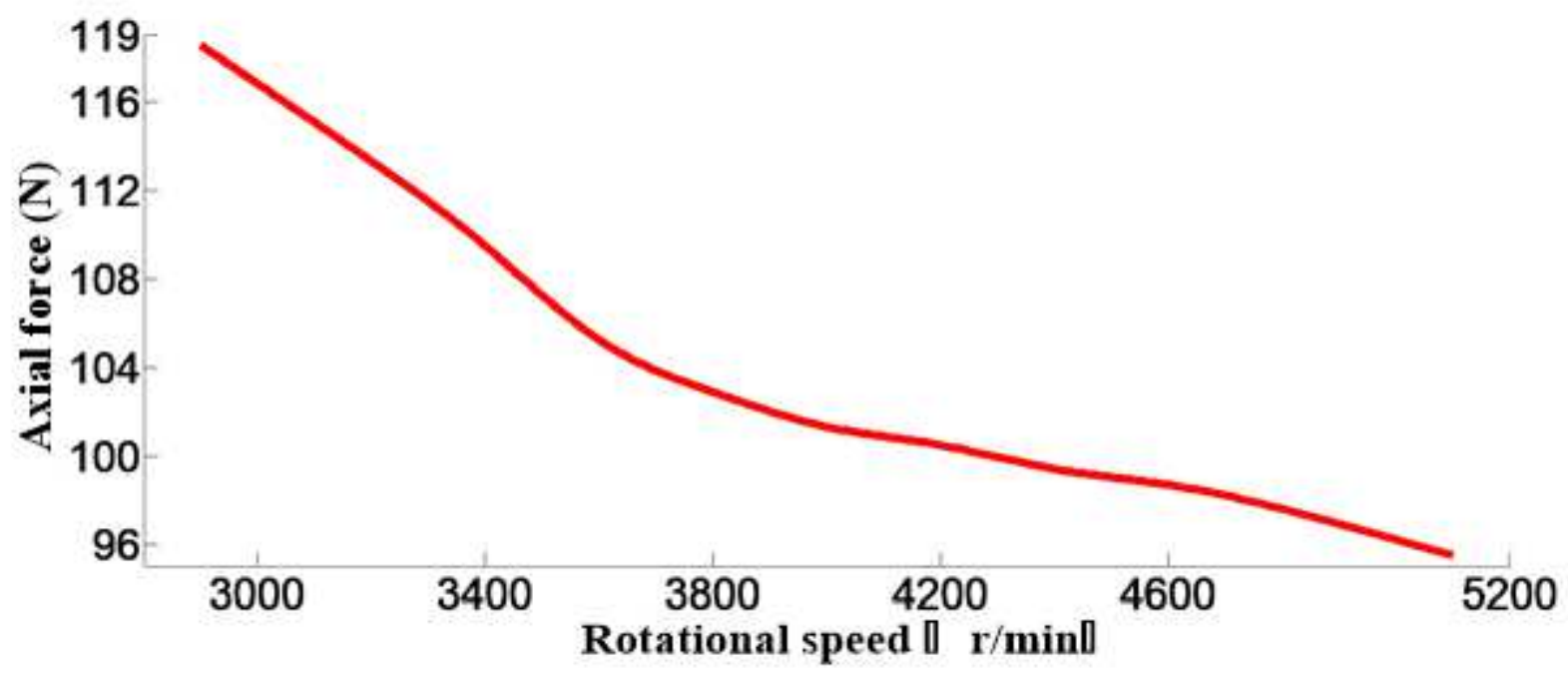

Figure 10

The curve of the change of the axial force versus the rotational speed 


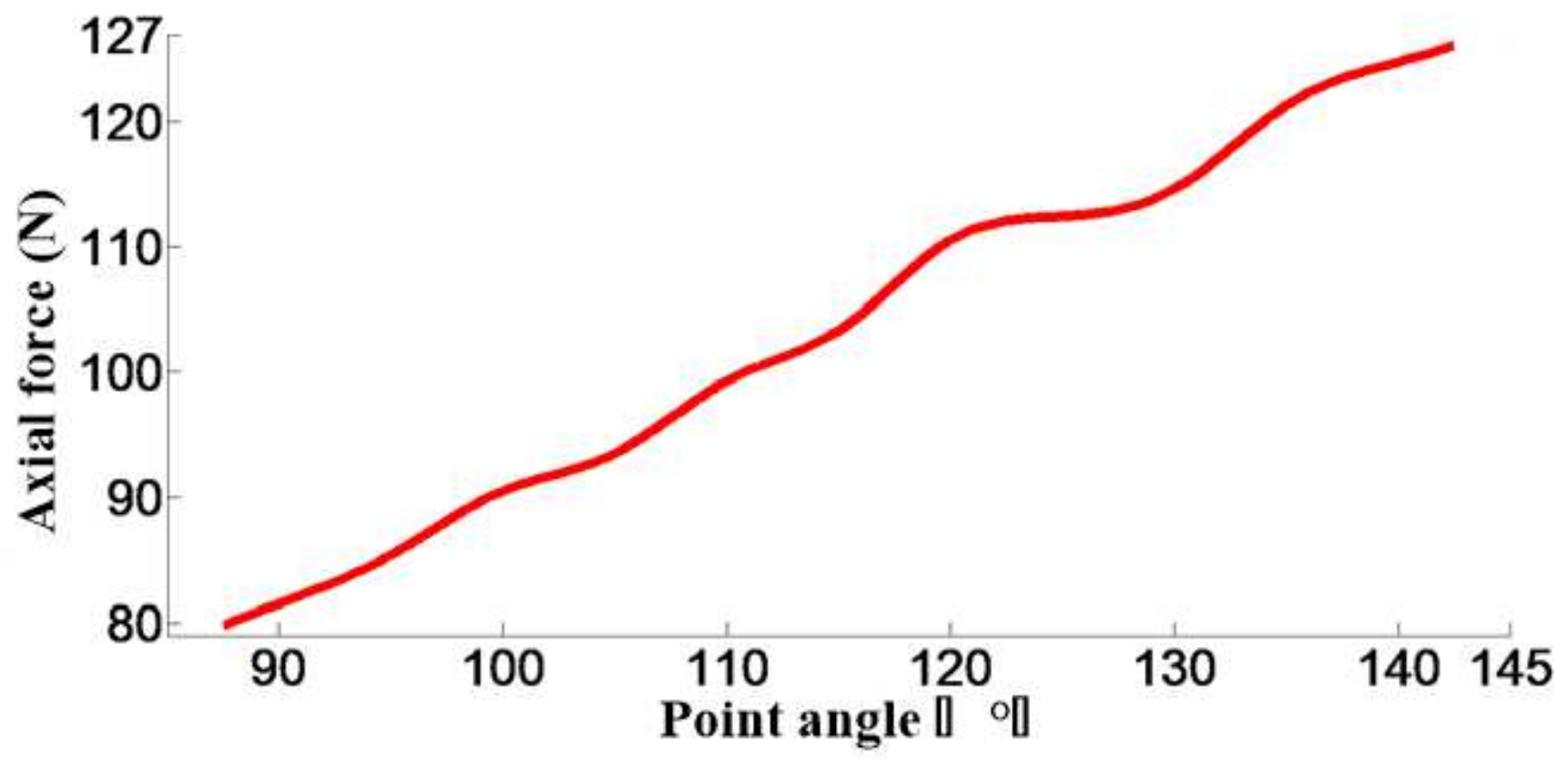

Figure 11

The curve of the change of the axial force versus the point angle

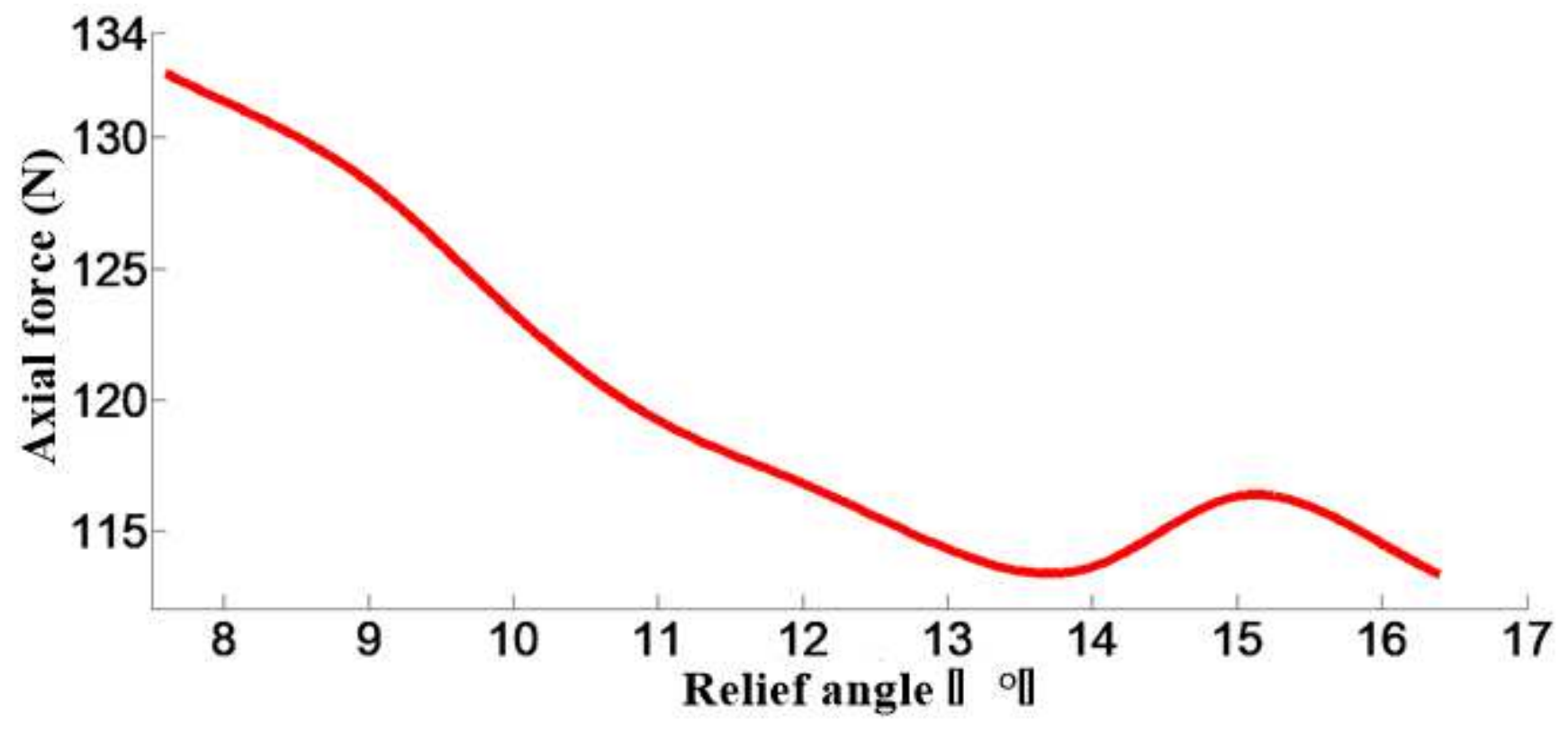

Figure 12

The curve of the change of the axial force versus the relief angle 


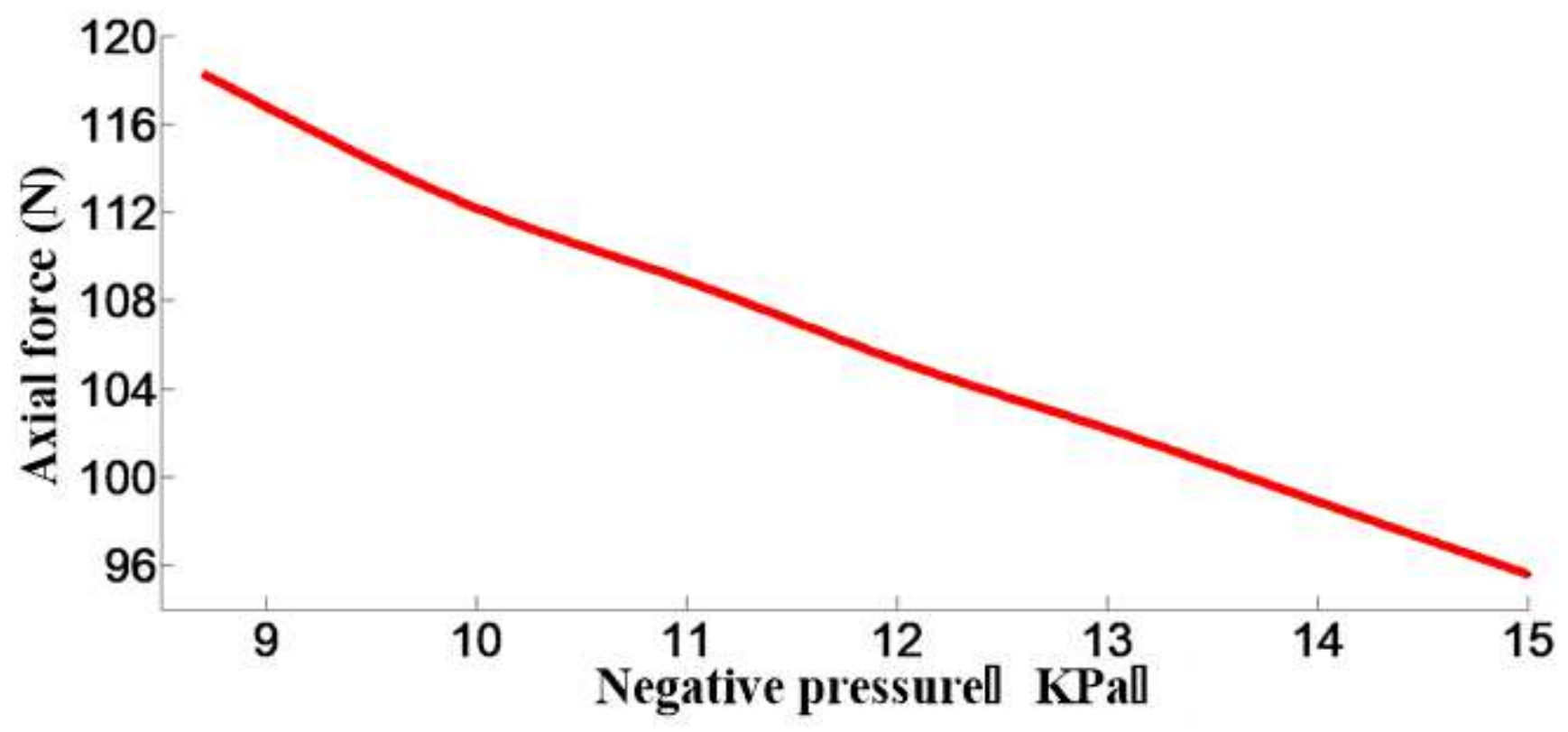

Figure 13

The curve of the change of the axial force versus the drilling negative pressure 